\title{
Review
}

\section{Oxygen-sensing mechanisms and the regulation of redox-responsive transcription factors in development and pathophysiology}

\author{
John J Haddad
}

Severinghaus-Radiometer Research Laboratories, Molecular Neuroscience Research Division, Department of Anesthesia and Perioperative Care, University of California at San Francisco, School of Medicine, Medical Sciences Building S-261, 513 Parnassus Avenue, San Francisco, California 94143-0542, USA

Correspondence: johnjhaddad@yahoo.co.uk

Received: 25 February 2002

Respir Res 2002, 3:26

Revisions requested: 25 April 2002

Revisions received: 20 May 2002

Accepted: 15 July 2002

Published: 22 November 2002
(Print ISSN 1465-9921; Online ISSN 1465-993X)

\begin{abstract}
How do organisms sense the amount of oxygen in the environment and respond appropriately when the level of oxygen decreases? Oxygen sensing and the molecular stratagems underlying the process have been the focus of an endless number of investigations trying to find an answer to the question: "What is the identity of the oxygen sensor?" Dynamic changes in $\mathrm{pO}_{2}$ constitute a potential signaling mechanism for the regulation of the expression and activation of reduction-oxidation (redox)-sensitive and oxygen-responsive transcription factors, apoptosis-signaling molecules and inflammatory cytokines. The transition from placental to lung-based respiration causes a relatively hyperoxic shift or oxidative stress, which the perinatal, developing lung experiences during birth. This variation in $\Delta p \mathrm{O}_{2}$, in particular, differentially regulates the compartmentalization and functioning of the transcription factors hypoxia-inducible factor- $1 \alpha$ (HIF-1 $\alpha$ ) and nuclear factor- $\kappa \mathrm{B}$ (NF- $\kappa \mathrm{B})$. In addition, oxygen-evoked regulation of $\mathrm{HIF}-1 \alpha$ and $\mathrm{NF}-\mathrm{KB}$ is closely coupled with the intracellular redox state, such that modulating redox equilibrium affects their responsiveness at the molecular level (expression/ transactivation). The differential regulation of HIF- $1 \alpha$ and NF- $\mathrm{BB}$ in vitro is paralleled by oxygensensitive and redox-dependent pathways governing the regulation of these factors during the transition from placental to lung-based respiration ex utero. The birth transition period in vivo and ex utero also regulates apoptosis signaling pathways in a redox-dependent manner, consistent with NF- $\kappa B$ being transcriptionally regulated in order to play an anti-apoptotic function. An association is established between oxidative stress conditions and the augmentation of an inflammatory state in pathophysiology, regulated by the oxygen- and redox-sensitive pleiotropic cytokines.
\end{abstract}

Keywords: apoptosis, cytokine, development, glutathione, HIF-1 $\alpha$, immunopharmacology, NF-кB, oxygen sensing, pathophysiology, redox equilibrium

\section{Introduction}

Living aerobic organisms, from prokaryotes to complex eukaryotes, have developed elaborate sequences of adaptive mechanisms to maintain oxygen homeostasis and equilibrium [1-3]. In mammals, for instance, the development of the respiratory and cardiovascular systems allows the acquisition and appropriate distribution of oxygen as a substrate for oxidative phosphorylation, the major biochemical reaction for the derivation of ATP (the vital biological currency necessary to maintain cell survival) $[3,4]$. As the terminal electron acceptor for oxidative phosphorylation, molecular oxygen occupies an essential role in many of the metabolic processes associated with aerobic existence [1-4]. The process of breathing is the initial step of respiration, which includes both the movement of oxygen from the lungs to the tissues and the process of cellular respiration that generates ATP [4]. 
The role of the lung in adult life is essentially one of gas exchange. This is an organ responsible for providing a moist epithelial barrier for the transport of atmospheric oxygen into the blood via a network of fine capillaries enveloping the alveolar sacs, while concomitantly removing from the body the accumulating waste, $\mathrm{CO}_{2}[5-7]$. The coneshaped lungs are divided into lobes, each of which is subdivided into lobules having bronchioles that serve many alveoli. Each alveolar sac is made up of simple squamous epithelium surrounded by blood capillaries, thereby allowing for efficient and rapid gas exchange across this barrier [5-8]. The development of a mature lung, therefore, is crucial for survival; within the context of an integral physiological system, tightly regulating the partial pressure of oxygen $\left(p \mathrm{O}_{2}\right)$ is important in the face of a continuously changing environment [4-10].

The airway epithelium, in particular, is not only an inert barrier but also a major participant in signaling mechanisms during development and under pathophysiological conditions [5-7,11-15]. Therefore, any damage caused to the airway epithelium can adversely affect its normal physiology and regulatory processes [6,7]. The major functions of the airway epithelium include the following: i) it is a dynamic physiological barrier to diffusion and osmotic processes; ii) it provides an integral metabolic function by synthesizing and degrading chemical components either endogenously produced or exogenously introduced; and iii) it possesses a secretory property in that the epithelium has an inherent capacity to produce mucus, cytokines and chemokines, hormones, growth factors and enzymes [6,7,11-15]. This underlines the significance of a physiologically competent epithelium, because metabolic failure or noxious damage would lead to abnormalities in the normal development and functioning of the lung [11-15].

The transition from placental to lung-based respiration causes a relatively hyperoxic shift or oxidative stress, which the perinatal, developing lung experiences during birth $[5,10,12-14]$. Dynamic changes in $p \mathrm{O}_{2}$, therefore, constitute a potential signaling mechanism for the regulation of the expression and activation of redox-sensitive transcription factors, apoptosis signaling and proinflammatory cytokines $[13,14,16-18]$. This review is primarily concerned with discussing the recent understanding of redox signaling and gene regulation, the role of oxygenation in determining cell fate (apoptosis) and the downstream, protracted inflammatory state.

\section{Lung maturation: an overview of prenatal and postnatal developmental stages}

The development of the human lung begins on approximately the 26th day of gestation (4 weeks after conception). Lung maturation continues postnatally and is not completed until late childhood (up to 8 years), although postnatal development generally consists of an increase in the number of mature alveoli $[5,8]$. The major stages of lung development, going from a glandular structure to an alveolar structure capable of efficient gaseous exchange with the capillary network, begin at the eighth week of gestation and continue to term (40 weeks) and postnatally [5]. The 32 weeks of gestational development are classified into stages in accordance with the visual appearance of lung tissue: embryonic, pseudoglandular, canalicular, saccular, and alveolar.

\section{Embryonic stage}

The embryonic stage of lung development ( 26 days $\approx 6$ weeks) begins when the respiratory diverticulum, or lung bud, appears as an outgrowth from the ventral wall of the foregut. This stage is followed by the separation of the lung bud from the foregut, thus forming the trachea (windpipe) and bronchial buds, which successively enlarge at the beginning of the fifth week to form the main bronchi. The embryonic stage is marked by the formation of the lobular and segmental sections of the respiratory tree as columnarepithelium-lined tubes evident by the end of the fifth or sixth week [5].

\section{Pseudoglandular stage}

The pseudoglandular stage roughly begins at the fifth/sixth week of gestation and lasts up until $16 \mathrm{th} / 17$ th week. What marks this period are the histological appearance of the fetal lungs as an exocrine gland and the completion of the proliferation of the primitive airways. At this stage, cartilage is formed around the larger airways and smooth muscles begin to envelop airways and blood vessels. Upon completion of this stage, acinar outlines first begin to appear as epithelial tubes continue to grow and branch. The undifferentiated columnar epithelial cells lining the tubular glandular structures are destined to evolve into the many cell types that populate the airways, including serous, goblet, ciliated, Clara and alveolar cells $[5,6,8]$.

\section{Canalicular stage}

The canalicular development stage comprises the period commencing on the 16 th/17th week and continuing to the 25th-27th weeks of gestation. The enlargement of the lumina of bronchi and terminal bronchioles characterizes the canalicular stage, in addition to the formation of capillaries at the site of the future air space and the appearance of surfactant, representing the major developments that are absolutely crucial to extra-uterine life. During this stage, in addition, the acini subdivisions are formed, and the epithelial lining begins to differentiate into alveolar type I (ATI) and II (ATII) cells $[5,6]$.

\section{Saccular stage}

The saccular stage, or terminal sac stage (28th-35th week of gestation), represents the development of terminal air sacs from alveolar ducts, refinement of gas exchange sites, 
a decrease in the thickness of the interstitium, thinning of the epithelium and separation of the terminal air units. This stage also marks the terminal differentiation stages of alveolar ATI and ATII epithelial cells.

\section{Alveolar stage}

The final 5 weeks of fetal lung development, termed the alveolar period, encompass the alveolar stage in which millions of alveoli are formed, with the surface area increased by thinning of the septal walls and attenuation of the cuboidal epithelium. The terminal subsaccules are now separated by loose connective tissue and cellular maturation continues specifically with ATII cells developing a greater density of lamellar bodies $[5,6]$.

\section{Differentiation of ATI and ATII cells}

Concomitant with the development of various lung structures is the cellular differentiation of ATI and ATII cells occurring as the alveolar epithelium matures. During the first four months of gestation the epithelial lining is more or less columnar to cuboidal [5-7]. By six months, ATI and ATII cells can be relatively distinguished in the more localized differentiated zones of pseudo-cuboidal cells.

\section{ATI cells}

ATI cells are thin, flat, squamous epithelia conspicuous because of the cells' small perinuclear body and long cytoplasmic extrusions; they are developed from the cuboidal cells that line bronchioles and cover most of the alveolar wall at later stages of development. ATI cells are characterized by having a low compliment of organelles, indicating low metabolic activity, thus reflecting the quiescent nature of these cells. The morphology of ATI cells, however, is suitably convenient to provide a large surface area with a small volume, ideal for rapid and efficient gas exchange.

\section{ATIl cells}

ATIl cells are identifiable owing to their granular and cuboidal appearance, as a result of the dense packing of cytoplasmic organelles (indicating metabolically active cells) and lamellar bodies, which are densely layered organelles that synthesize and store pulmonary surfactants [5-8]. The major function of a surfactant, which is a mixture of proteins and the lipid disaturated dipalmitoyl phosphatidylcholine, is to reduce the surface tension, thus facilitating lung expansion during inhalation. Although ATIl cells are small in diameter $\left(\approx 400 \mu \mathrm{m}^{3}\right.$ in rat and $\approx 900 \mu \mathrm{m}^{3}$ in human), they are essential for proper gas exchange. Situated at the corners of the alveolar sacs, ATII cells represent little obstruction to gaseous diffusion and are fed by a capillary network. Intracellularly, these cells are richly endowed with cytoplasmic organelles associated with the biosynthesis of surfactant phospholipid and related proteins. In summary, ATIl cells function to serve as thin, gas-permeable entities for diffu- sion and act as a protective barrier against water and electrolyte leakage [5-7].

\section{Lung responses during the transition from pla- cental to lung-based respiration}

The fetal lung develops as a fluid-filled organ and is continuously situated in an environment that is relatively hypoxic $\left(\leq 3 \% \mathrm{O}_{2}\right)$, which is the potential oxygen-carrying capacity of the umbilical vein $[5,8,10,13]$. When ex utero respiration commences, most of the lung fluid is reabsorbed into blood and lymph capillaries, allowing the newborn to breathe normally. Postnatal lung development continues and the $\approx$ 50 million alveoli at birth, which have a surface area of 3-4 $\mathrm{m}^{2}$, represent $\approx 15-20 \%$ of the 300 million alveoli present in the adult lung (surface area $\approx 75-100 \mathrm{~m}^{2}$ ) [5]. At birth, the lung undergoes a dramatic change from a fluid-filled to a gas-filled organ, thereby subjecting the neonate's lung to a transition from a relatively hypoxic environment to one that is hyperoxic $\left(10-15 \% \mathrm{O}_{2}\right)[5,8,10,19,20]$.

The transition from placental to lung-based respiration is perceived as normal in fully mature babies; in contrast, preterm infants may suffer tremendously as the lungs may be insufficiently developed, and may be incapable of sustaining normal breathing $[8,10,13,15]$. The preterm neonate can suffer from a variety of clinical illnesses and may develop chronic lung diseases caused by the supplementation of exogenous oxygen $[5,8,10,15]$. The transition from placental to lung-based respiration, therefore, constitutes a potential signaling mechanism for the continuation of lung development and maturation while the lung experiences dramatic and dynamic variations in $p \mathrm{O}_{2}[5,8,10,15,20]$.

During normal breathing, the incomplete reduction of inhaled oxygen may lead to accumulation of toxic reactive oxygen species (ROS) that may contribute to capillary injury and lung tissue perturbations [8,21-25]. All forms of aerobic life are thus faced with the threat of oxidation from atmospheric molecular oxygen and have developed elaborate mechanisms of antioxidant defenses to cope with this potential problem $[2,3,16-18,22,26]$. Any deviation from homeostasis, or physiological changes in $p \mathrm{O}_{2}$, is recognized as an exposure to oxidative stress [1-3,16-18,2731]. In particular, key developmental changes in the lategestation (preterm) lung have evolved to allow production of surfactants and enzymatic and non-enzymatic antioxidants in preparation for the first breaths at birth $[5,8,10,21,32]$. Moreover, the maturation chronology of the lung antioxidant system parallels that of the prenatal maturation of the surfactant system, highlighting the stages developing fetuses undergo in order to prepare for birth into an oxygen-rich environment $[5,8,10,20]$. Apparently, any perturbations in maintaining homeostatic mechanisms in response to changes in oxygen levels are critical in determining cellular characteristic integrity. The clinical, biochemical and histologic responses of the lungs to such 
variations consequently characterize the efficiency and specificity of the antioxidant system in combating stress $[5,8,10,16-18]$. For example, in certain lung pathophysiological conditions, oxygenation of terminal airways becomes uneven, such that this temporal and spatial variance in oxygen abundance essentially determines the survival of the lung cells via oxygen-dependent activation of cell regulators and genes critical to defending their structural/functional characteristics $[5,8,10,13,14,16-18,21-23,26,27]$.

\section{Oxygen homeostasis and adaptation mecha- nisms: implications for oxidative stress and pathophysiology \\ Oxidative stress}

Accumulating evidence in recent years has linked the pathogenesis of some human diseases to increased oxidative stress $[5,8,15,22,27,33-36]$. In particular, ROS, which are partially reduced metabolites of oxygen consumption, may contribute to alveolar-capillary membrane disturbances and the development of lung injury $[5,8,10,22,35]$. A wealth of data has drawn attention to both the significance of maintaining reducing conditions in cells and the fight against the damaging effect of ROS intermediates [17,22,35,37-39]. Oxidants, for instance, can cause carcinogenesis, sclerosis, Alzheimer's disease and other neurological disorders, acute lung injury and chronic lung diseases $[5,8,17,22,27,33,37,38]$. Oxidative cell injury involves the modification of cellular macromolecules by ROS, often leading to cell death and the lysis of sensitive cells, resulting in microvascular and alveolar perturbations $[5,8,17,22,38,39]$. Oxidative stress appears to increase in the lung, the level of antioxidants in some experimental models, and hypoxia and hyperoxia modulate fetal lung growth $[14,16,17,21,23,27]$. Furthermore, there is growing evidence supporting the concept of cross-talk between oxidative stress and upregulation of a proinflammatory signal through the participation of cytokines [34-36,39-44].

\section{Cytokines}

Cytokines are peptide hormones that participate in autocrine and paracrine signaling $[42,43,45,46]$. They are major participants in the pathophysiology of respiratory distress and have been recognized as signaling molecules responsive to dynamic variation in $\mathrm{pO}_{2}[34,35,39-42,44]$. Examples of such cytokines are interleukin (IL)-1 $\beta$, IL-6, IL8 , tumor necrosis factor (TNF)- $\alpha$, transforming growth factor, and granulocyte-macrophage colony-stimulating factor. Cytokines and other inflammatory mediators play important (not necessarily inflammation-related) roles not only during fetal life, but also in the initiation of labor and in neonatal immunity and diseases $[36-38,40,42,45,46]$. Hematopoietic growth factors, for example, regulate the maturation of progenitors in fetal and neonatal hematopoietic organs $[36,42,45]$. Cytokines act as extrahematopoietic growth factors and as modulators of fetomaternal tolerance and are involved in selective apoptosis during tis- sue remodeling [34,36-38]. Inter-regulation of cytokine networks is therefore critical for normal function and maturation of neonatal host defenses. Neonates initially depend on natural (innate) immunity and antigen-specific immunity develops later in life $[36,42,45,46]$. Cytokines regulate innate immunity and connect it with antigen-specific adaptive immunity $[34,36,45,46]$. This integral association between oxidative stress and a proinflammatory state may affect cellular redox equilibrium, thereby imposing a direct role in modulating the pattern of gene expression in lung tissues; accordingly, this could be pivotal in determining cellular fate under these conditions [2,3,13,14,16$19,26,27,34,39-46]$.

\section{Antioxidants}

As the fetus leaves the hypoxic environment and enters the relatively hyperoxic environment during the transition from placental to lung-based respiration, it is imperative that it develops antioxidant mechanisms to guard against the potential harm posed by oxygen-derived species $[13,14,19,20]$. Defense mechanisms include, for example, the reduction of ROS by antioxidant enzymes such as catalase, manganese-, copper- and zinc-containing superoxide dismutase (Mn-SOD/Cu-SOD/Zn-SOD), and the redox-sensitive enzyme glutathione peroxidase $[2,3,13,16-$ $19,27,37]$. ROS may not, however, pose a real threat to the fetus if these endproducts are detoxified and balanced against the amount of ROS generated $[22,27,37,38,40]$.

In keeping with this idea, the tripeptide L- $\gamma$-glutamyl-Lcysteinyl-glycine, or glutathione (GSH), a ubiquitous thiol, plays an important role in maintaining intracellular redox equilibrium and has evolved as one of the major detoxifying antioxidants and abundant thiols in almost all mammalian cells $[13,14,40,41,47-50]$. Glutathione determines intracellular redox potential and detoxifies harmful ROS by the glutathione-peroxidase-coupled reaction (Fig. 1). Oxygen signaling across membranes of intercellular compartments may be linked to a certain redox state that might be crucial in regulating the magnitude and pattern of gene expression of oxygen- and redox-responsive transcription factors $[2,3,13,14,16-19]$. Such transcription factors are implicated in determining cellular responses under both physiological and pathophysiological conditions $[2,3,16-$ $18,27,37,51]$.

Redox-sensitive transcription factors are therefore likely to be differentially regulated by oxygen availability, to bind specific DNA consensus sequences and to activate the expression of several genes, particularly those controlling adaptive homeostasis in a hostile environment $[2,3,16-$ $18,51]$. Among such factors, HIF-1 $\alpha$ and NF-kB, whose activation states are differentially regulated under oxidative stress [52-55] are particularly important. HIF- $1 \alpha$, first identified in vitro through its DNA-binding activity expressed 


\section{L-Glutamate $+{ }_{L}-$-Cysteine \\ BSO $\longrightarrow \gamma$-GCS $\longrightarrow \longleftarrow$ ATP \\ L- $\gamma$-Glutamyl-L-cysteine}

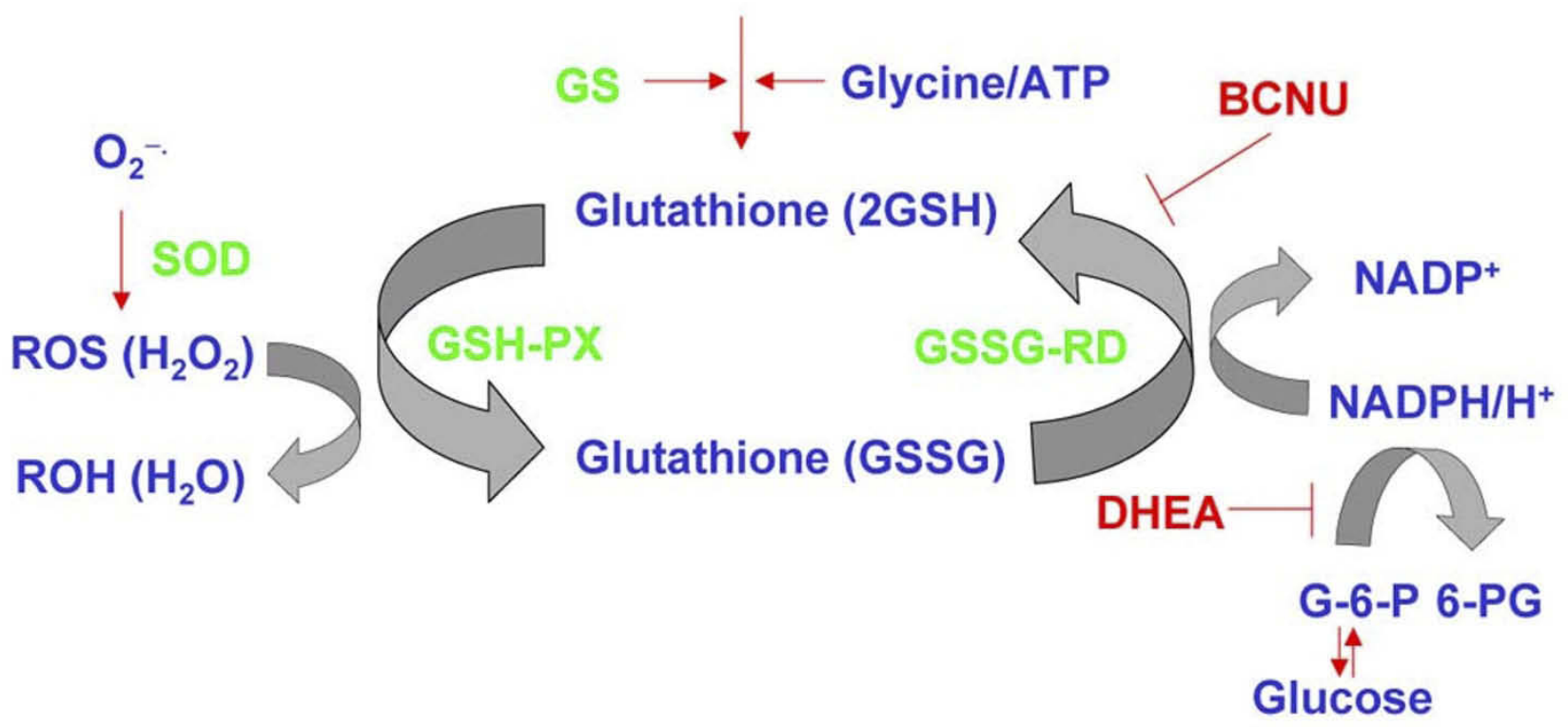

Respiratory Research

The schematic of the redox cycle shows the relationship between antioxidant enzymes and glutathione. All enzymes are shown in green, substrates and products in blue, and inhibitors in red. Glutathione (GSH) is synthesized from amino acids by the action of $\gamma$-glutamylcysteine synthetase $(\gamma$ GCS), the rate-limiting enzyme, and glutamyl synthase (GS). This reaction requires energy, is ATP-limited and is specifically inhibited at the level of $\gamma$ -

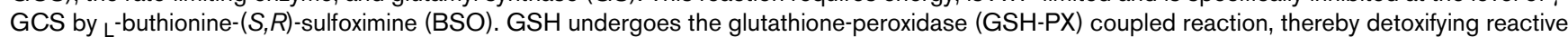
oxygen species (ROS) such as hydrogen peroxide $\left(\mathrm{H}_{2} \mathrm{O}_{2}\right)$. A major source of $\mathrm{H}_{2} \mathrm{O}_{2}$ is the biochemical conversion of superoxide anion $\left(\mathrm{O}_{2}^{-\bullet}\right)$ by the action of superoxide dismutase (SOD). During this reaction, GSH is oxidized to generate GSSG, which is recycled back to GSH by the action of glutathione reductase (GSSG-RD) at the expense of reduced nicotinamide $\left(\mathrm{NADPH} / \mathrm{H}^{+}\right)$, thus forming the redox cycle. The reduction of the glutathione pathway is blocked by the action of 1,3-bis-(2-chloroethyl)-1-nitrosourea (BCNU). The major source of NADPH/ $\mathrm{H}^{+} \mathrm{Comes}$ from the conversion of glucose, a reaction blocked by dehydroepiandrosterone (DHEA).

under hypoxic conditions [56] has its concentration and activity increased exponentially when oxygen tensions are decreased over physiologically relevant ranges [51-53]. The ubiquitous activation of HIF- $1 \alpha$ is thus consistent with the significant role that this factor plays in coordinating adaptive responses to hypoxia [52,53]. NF- $\mathrm{KB}$, on the other hand, was first identified as a transcription factor that regulates antibody release in B cells [57]. It is central to the regulation and expression of stress-response genes in the face of inflammatory and oxidative challenge $[13,14,16-$ $19,27,54,55,58]$. Oxygen and redox regulation of HIF-1 $\alpha$ and NF-KB will be comprehensively discussed after a brief discussion of the regulation of oxygen-sensing mechanisms.

\section{The regulation of oxygen sensing mechanisms}

Oxygen sensing and its underlying molecular stratagems have been the focus of experimental investigations trying to find an answer to the question: "What is the identity of the oxygen sensor?" [1-3,29-31,59-63]. The first molecular mechanism to be proposed to underlie oxygen sensing in mammalian cells involves an oxygen sensor that is a heme protein [1-3,59-61]. Studies on erythropoietin (EPO), a glycoprotein hormone required for the proliferation and dif- 


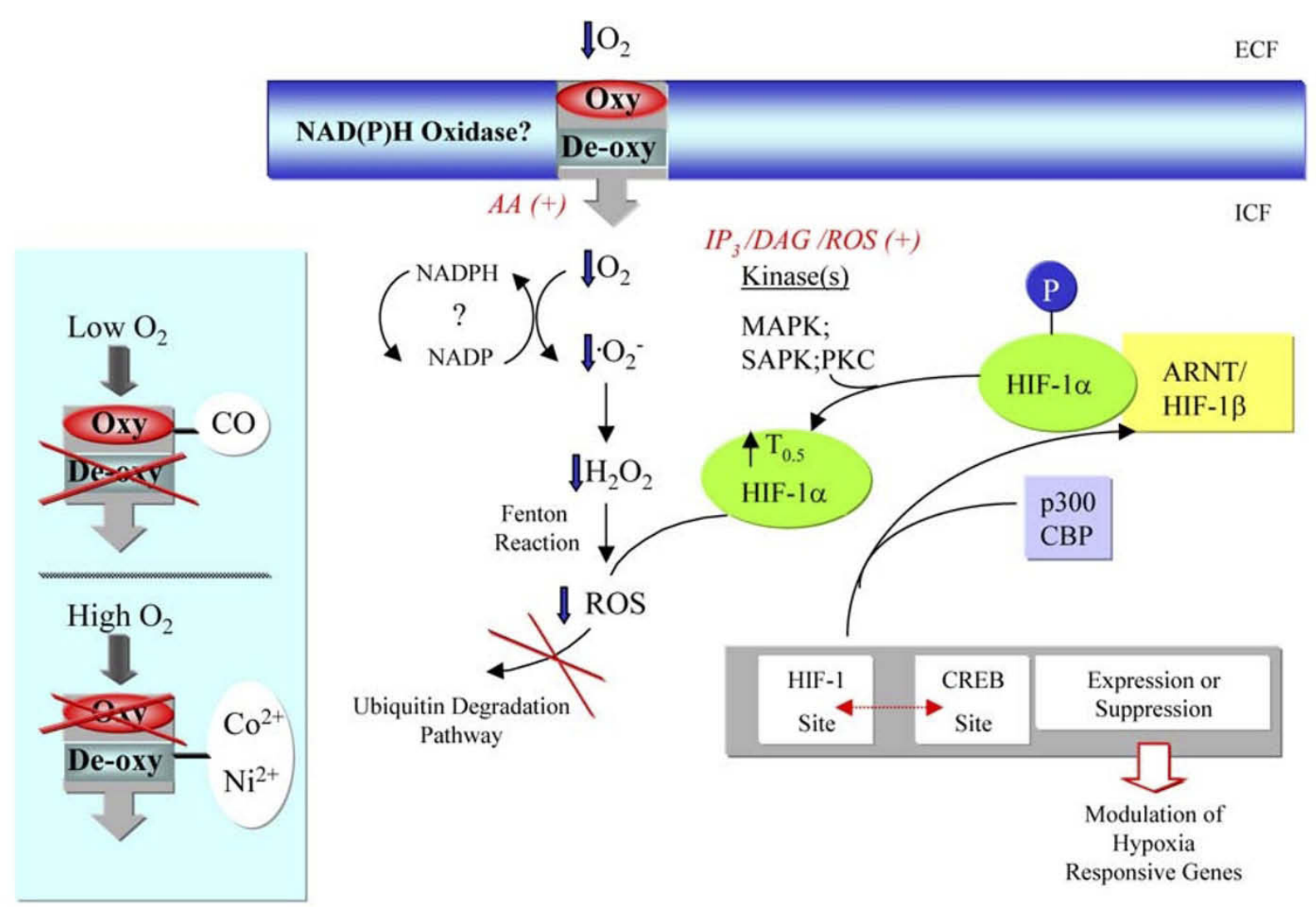

Respiratory Research

Proposed oxygen-sensing mechanisms for the regulation of gene transcription and the involvement of HIF-1 as a hypoxia-mediated transcription factor. See main text for further details. The thick 'down' arrows indicate a reduction in the amount of the molecule shown. [AQ18] CO might affect oxygen sensing by locking the sensor (shown as Oxy/De-oxy in the plasma membrane and the inset) in an oxy conformation. $\mathrm{Co}^{2+} / \mathrm{Ni}^{2+}$ might affect oxygen sensing by locking the sensor in a de-oxy conformation. AA, arachidonic acid; ARNT, aryl hydrocarbon receptor nuclear translocator; CREB, cAMP-responsive element binding protein; CBP, CREB-binding protein; DAG, diacyl glycerol; ECF, extracellular fluid; HIF-1, hypoxia-inducible factor-1; ICF, intracellular fluid; $\mathrm{IP}_{3}$, inositol triphosphate; MAPK, mitogen-activated protein kinase; $\mathrm{O}_{2} \cdot \bullet$, superoxide anion; $\mathrm{P}$, phosphorylation; PKC, protein kinase C; ROS, reactive oxygen species; SAPK, stress-activated protein kinase; $\mathrm{T}_{0.5}$, half-life.

ferentiation of erythroid cells, demonstrated that EPO production is enhanced under hypoxic conditions $[52,53,59,61,64,65]$. EPO expression can be induced by transition metals such as cobalt $\left(\mathrm{Co}^{2+}\right)$ and nickel $\left(\mathrm{Ni}^{2+}\right)$, supporting the hypothesis that these metal atoms can substitute for the iron atom within the heme moiety, and that the oxygen sensor for the induction of EPO is a heme protein $[59-61,64,65]$. Further evidence supporting the notion that the oxygen sensor is a heme protein came with additional studies that utilized carbon monoxide (CO); $\mathrm{CO}$ can noncovalently bind to ferrous $\left(\mathrm{Fe}^{2+}\right)$ heme groups in hemoglobin, myoglobin, cytochromes and other heme proteins [59-63] where its ligation state is structurally identical to that of oxygen. It was subsequently proposed that $\mathrm{CO}$ might affect oxygen sensing by locking the sensor in an oxy conformation, which could involve a multisubunit mechanism [59-65] (Fig. 2).

\section{Potential involvement of a microsomal mixed-function oxidase}

In addition to the aforementioned models for oxygen sensing, certain pharmacological studies, led by Fandrey and colleagues [66] suggest that the oxygen sensor might involve a microsomal mixed-function oxidase. Based on these studies, it was proposed that oxygen sensing for EPO involves an interaction between cytochrome P450 and cytochrome $\mathrm{P} 450$ reductase, thereby allowing the conversion of molecular oxygen to superoxide anion $\left(\mathrm{O}_{2}^{-\bullet}\right)$ and hydro- 
gen peroxide $\left(\mathrm{H}_{2} \mathrm{O}_{2}\right)$ radicals [59,61,66,67]. Acker [59] has provided support based on spectroscopic evidence for the central role of an oxidase in oxygen sensing. It was reported that $b$-cytochrome functions as a $\mathrm{NAD}(\mathrm{P}) \mathrm{H}$ oxidase, converting oxygen to $\mathrm{O}_{2} \cdot \bullet$. The enzymatic complex in mammalian cells is membrane-bound and transduces the conversion of molecular oxygen to ROS, according to the following equations:

$$
\begin{aligned}
& \mathrm{CytFe}^{2+}+\mathrm{O}_{2} \rightarrow \mathrm{CytFe}^{2+} \mathrm{O}_{2} \\
& \mathrm{CytFe}^{2+} \mathrm{O}_{2} \rightarrow \mathrm{CytFe}^{3+}+\mathrm{O}_{2} \cdot \\
& \mathrm{CytFe}^{3+}+\mathrm{NAD}(\mathrm{P}) \mathrm{H} \rightarrow \mathrm{CytFe}^{2+}+\mathrm{NAD}(\mathrm{P})+
\end{aligned}
$$

\section{Potential involvement of the mitochondria}

A resurgence of interest in mitochondrial physiology has recently developed as a result of new experimental data demonstrating that mitochondria function as important participants in a diverse collection of novel intracellular signaling pathways. Further experiments showed a potential involvement of the mitochondria in oxygen sensing [68]. For instance, a spectroscopic photolysis with monochromatic light has identified a CO-binding heme protein falling within the spectrum of the mitochondrial cytochrome $a_{3}[69]$. It was consequently proposed that this heme protein, presumably located on the plasma membrane, has a low affinity for oxygen and a relatively high affinity for CO (Fig. 2). The same model predicted that another heme protein in the mitochondria has a relatively higher affinity for oxygen and a lower affinity for $\mathrm{CO}$ [59-70]. The biochemical reaction, which was proposed as an alternative way of regenerating ferroheme in the oxygen sensor, is given below:

$\mathrm{CO}+2 \mathrm{Fe}^{3+}+\mathrm{H}_{2} \mathrm{O} \rightarrow \mathrm{CO}_{2}+2 \mathrm{Fe}^{2+}+2 \mathrm{H}^{+}$

These aforementioned observations pertaining to the mitochondrion as a possible oxygen sensor were unequivocally supported by novel studies recently reported by Schumacker, Chandel and colleagues [71-76]. Cardiomyocytes are known to suppress contraction and oxygen consumption during hypoxia [71]. Cytochrome oxidase undergoes a decrease in $V_{\max }$ during hypoxia, which could alter mitochondrial redox status and increase generation of ROS. Duranteau and colleagues [71] tested whether ROS generated by mitochondria act as second messengers in the signaling pathway linking the detection of oxygen with the functional response. Contracting cardiomyocytes were superfused under controlled oxygen conditions while fluorescence imaging of 2,7-dichlorofluorescein was used to assess ROS generation. Compared with normoxia, graded increases in 2,7-dichlorofluorescein fluorescence were seen during hypoxia. In addition, the antioxidants 2-mercaptopropionyl glycine and 1,10-phenanthroline attenuated these increases and abolished the inhibition of contraction.
Superfusion of normoxic cells with $\mathrm{H}_{2} \mathrm{O}_{2}$ mimicked the effects of hypoxia by eliciting decreases in contraction that were reversible. To test the role of cytochrome oxidase, sodium azide was added during normoxia to reduce the $\mathrm{V}_{\max }$ of the enzyme. It was observed that azide produced graded increases in ROS signaling, accompanied by graded decreases in contraction that were reversible, demonstrating that mitochondria respond to graded hypoxia by increasing the generation of ROS and suggesting that cytochrome oxidase may contribute to this oxygen sensing mechanism [71].

The same group also recently reported that mitochondrial ROS trigger hypoxia-induced transcription. Chandel et al.[72] tested whether mitochondria act as oxygen sensors during hypoxia and whether hypoxia and $\mathrm{CO}$ activate transcription by increasing generation of ROS. Results showed that wild-type Hep3B cells increased ROS generation during hypoxia or $\mathrm{CoCl}_{2}$ incubation. Hep3B cells depleted of mitochondrial DNA ( $\rho^{0}$ cells) failed to respire, failed to activate mRNA for EPO, glycolytic enzymes or vascular endothelial growth factor (VEGF) during hypoxia and failed to increase ROS generation during hypoxia. The $\rho^{0}$ cells increased ROS generation in response to $\mathrm{CoCl}_{2}$ and retained the ability to induce expression of these genes. The antioxidants pyrrolidine dithiocarbamate (PDTC) and ebselen, a glutathione peroxidase mimetic, abolished transcriptional activation of these genes during hypoxia or $\mathrm{CoCl}_{2}$ in wild-type cells and abolished the response to $\mathrm{CoCl}_{2}$ in $\rho^{0}$ cells [72]. It was proposed that hypoxia activates transcription via a mitochondria-dependent signaling process involving increased ROS, whereas $\mathrm{CoCl}_{2}$ activates transcription by stimulating ROS generation via a mitochondriaindependent mechanism [72-74].

In another interesting observation, Chandel and colleagues reported that mitochondrial ROS play a major role in HIF$1 \alpha$ regulation [75]. In this respect, it was observed that hypoxia increased mitochondrial ROS generation at Complex III, which caused the accumulation of HIF- $1 \alpha$ protein responsible for initiating expression of a luciferase reporter construct under the control of a hypoxic response element [75]. Of note, this response was lost in cells depleted of mitochondrial DNA. Furthermore, overexpression of catalase abolished expression of the hypoxic response element-luciferase construct during hypoxia. In addition, exogenous $\mathrm{H}_{2} \mathrm{O}_{2}$ stabilized HIF- $1 \alpha$ protein during normoxia and activated luciferase expression in wild type and $\rho 0$ cells. In fact, isolated mitochondria increased ROS generation during hypoxia, indicating that mitochondria-derived ROS are both required and sufficient to initiate HIF- $1 \alpha$ stabilization during hypoxia, thereby implicating this transcription factor as a possible oxygen sensor (see below) [70-76]. 


\section{A nonmitochondrial oxygen sensor}

A nonmitochondrial oxygen sensor has, however, been recently proposed. Ehleben and colleagues applied biophysical methods like light absorption spectrophotometry of cytochromes, determination of $\mathrm{NAD}(\mathrm{P}) \mathrm{H}$-dependent $\mathrm{O}_{2} \cdot{ }^{-}$ formation and localization of $\cdot \mathrm{OH}$ by three-dimensional (3D) confocal laser scanning microscopy to reveal putative members of the oxygen sensing signal pathway leading to enhanced gene expression under hypoxia $[4,77]$. A cell membrane localized nonmitochondrial cytochrome b558 seemed to be involved as an oxygen sensor in the hepatoma cell line HepG2 in cooperation with the mitochondrial cytochrome b563, probably probing additional metabolic changes. The hydroxyl radical $(\bullet \mathrm{OH})$, a putative second messenger of the oxygen-sensing pathway generated by a Fenton reaction, could be visualized in the perinuclear space of the three human cell lines used.

Substances like cobalt or the iron chelator desferrioxamine, which have been applied in HepG2 cells to mimic hypoxiainduced gene expression, interact on various sides of the oxygen-sensing pathway, confirming the importance of btype cytochromes and the Fenton reaction. Furthermore, NADPH oxidase isoforms with different gp91 phox subunits, as well as an unusual cytochrome aa3 with a heme:aa3 ratio of 9:91, have been discussed as putative oxygen sensor proteins influencing gene expression and ion channel conductivity [78]. ROS are believed to be important second messengers of the oxygen-sensing signal cascade determining the stability of transcription factors or the gating of ion channels. The formation of ROS by a perinuclear Fenton reaction was imaged by one- and two-photon confocal microscopy, revealing both mitochondrial and nonmitochondrial generation.

\section{The carotid body response to oxygen}

In reference to the aforementioned observation [78] some recent concepts on oxygen sensing mechanisms at the carotid body chemoreceptors have been highlighted $[1,79]$. Most available evidence suggested that glomus (type I) cells are the initial sites of transduction and they release transmitters in response to hypoxia, which in turn depolarize the nearby afferent nerve ending, leading to an increase in sensory discharge. Two main hypotheses have been advanced to explain the initiation of the transduction process that triggers transmitter release. One hypothesis assumed that a biochemical event associated with a heme protein triggers the transduction cascade. Supporting this idea, it has been shown that hypoxia might affect mitochondrial cytochromes. In addition, there was a body of evidence implicating nonmitochondrial enzymes such as NADPH oxidases, nitric oxide (NO) synthases and heme oxygenases located in glomus cells [79]. These proteins could contribute to transduction via generation of ROS, $\mathrm{NO}$ and/or $\mathrm{CO}$. The other hypothesis suggested that a $\mathrm{K}^{+}$ channel protein is the oxygen sensor and inhibition of this channel and the ensuing depolarization is the initial event in transduction, as indicated by Peers and Kemp [1].

Several oxygen-sensitive $\mathrm{K}^{+}$channels have been identified. Their roles in the initiation of the transduction cascade and/ or in cell excitability remain unclear. In addition, recent studies indicated that molecular oxygen and a variety of neurotransmitters might also modulate $\mathrm{Ca}^{2+}$ channels [79]. Most importantly, it is possible that the carotid body response to oxygen requires multiple sensors, and they work together to shape the overall sensory response of the carotid body over a wide range of arterial oxygen tensions.

The hypothesis that there exists a specific oxygen sensor(s), which relay(s) chemical signals intracellularly, is consistent with the notion that there is a unifying mechanism involved in transducing dynamic changes in $p \mathrm{O}_{2}$ to the nucleus [70]. In response to $\Delta p \mathrm{O}_{2}$, there is a coordinate expression of genes needed to confer appropriate responses to hypoxia or hyperoxia $[2,3,13,14,16-19,26,27,52-55]$. The regulation of physiologically important oxygen-responsive and redox-sensitive genes would, therefore, dictate well controlled responses of the cell within a challenging environment and necessarily would determine the specificity of cellular adaptation $[1-3,16-20,28,29,59-61,70-79]$.

\section{Oxygen responsiveness of regulatory transcrip- tion factors: molecular aspects}

How do organisms sense the amount of oxygen in the environment and respond appropriately when the amount of oxygen decreases (a condition called hypoxia)? The expression of genes is predominantly determined by conditions of the cellular microenvironment $[2,3,16-$ $20,27,28,34,51,58]$. Prime examples of such regulation are found in embryonic development of all multicellular organisms. The naturally occurring regulating agents, for example, interact with specific receptors, which subsequently transduce a signal into the nucleus for the regulation of gene expression and activation. The putative oxygen sensor responds to dynamic variation in $\mathrm{OO}_{2}$ such as those occurring during the birth transition period [1-3,16$20,19,20,59,61,70-79]$. Upon ligand binding, this presumably membrane-bound receptor transduces intracellular chemical/redox signals that relay messages for the regulation of gene expression, a phenomenon mainly involving the activation of transcription factors $[2,13,14,16-$ $18,26,34,51,70]$.

\section{Oxygen homeostasis and HIF-1 $\alpha$ regulation}

In order to maintain oxygen homeostasis, a process that is, of course, essential for survival, $\mathrm{pO}_{2}$ delivery to the mitochondrial electron transport chain must be tightly maintained within a narrow physiological range $[2,3,28,34,70]$. This system may fail with subsequent induction of hypoxia, resulting either in a failure to generate sufficient ATP to sus- 
tain metabolic activities or in a hyperoxic condition that contributes to the generation of ROS, which, in excess, could be cytotoxic and often cytocidal [5,8,22,34]. Adaptive responses to hypoxia involve the regulation of gene expression by HIF- $1 \alpha$, the expression, stability and transcriptional activity of which increase exponentially on lowering $\mathrm{pO}_{2}[52,53,56,80,81]$.

HIF- $1 \alpha$ is a mammalian transcription factor expressed uniquely in response to physiologically relevant hypoxic conditions [52,53,56,64,67,70-81]. Studies of the EPO gene led to the identification of a cis-acting hypoxia-response element (HRE) in its 3 '-flanking region $[52,53,67,80,81]$ and HIF-1 was identified through its hypoxia-inducible HRE-binding activity [56]. The HIF-1 binding site was subsequently used for purification of the HIF$1 \alpha$ and HIF-1 $\beta$ subunits by DNA affinity chromatography. Both HIF-1 subunits are basic helix-loop-helix PAS (an acronym for the first three family members, namely Per/ARNT/ Sim) proteins: HIF- $1 \alpha$ is a novel protein; HIF- $1 \beta$ is identical to the aryl hydrocarbon receptor nuclear translocator protein. HIF-1 $\alpha$ DNA-binding activity and HIF-1 $\alpha$ protein expression are rapidly induced by hypoxia and the magnitude of the response is inversely related to $\mathrm{pO}_{2}[52,53,56,64,67,70-83]$.

In hypoxia, multiple systemic responses are induced, including angiogenesis, erythropoiesis and glycolysis $[52,53,56,71-73]$. HREs containing functionally essential HIF-1-binding sites are identified in genes encoding VEGF, glucose transporter 1 , and the glycolytic enzymes aldolase $A$, enolase 1 , lactate dehydrogenase $A$ and phosphoglycerate kinase $1[51-53,64,65,72,73]$. HIF- $1 \alpha$ is an important mediator for increasing the efficiency of oxygen delivery through EPO and VEGF $[52,53]$. A well-controlled process of adaptation to hypoxia enables oxygen to be delivered more efficiently, through upregulation of EPO and VEGF and the expression and activation of glucose transporters and glycolytic enzymes $[52,53,64,65]$. EPO is responsible for increasing blood oxygen-carrying capacity by stimulating erythropoiesis; VEGF is a transcriptional regulator of vascularization; and glucose transporters and glycolytic enzymes increase the efficiency of anaerobic generation of ATP [51-53].

HIF- $1 \alpha$ has also been shown to activate transcription of genes encoding inducible nitric oxide synthase and heme oxygenase-1 (which are responsible for the synthesis of the vasoactive molecules $\mathrm{NO}$ and $\mathrm{CO}$, respectively), as well as the gene encoding transferrin (which, like EPO, is essential for erythropoiesis) [52,53]. Each of these genes contains an HRE sequence of $<100$ base pairs that includes one or more HIF-1-binding sites containing the core sequence 5'RCGTG-3' [51-53]. It is expected that any reduction of tissue oxygenation in vivo and in vitro would therefore provide
Figure 3

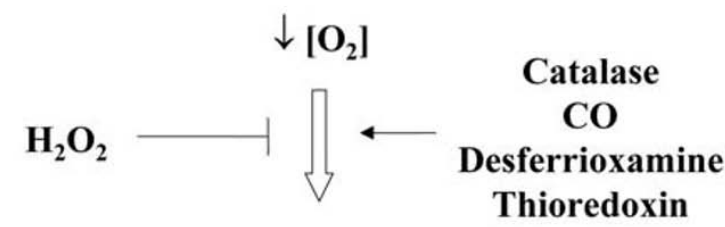

$\Delta$ Redox

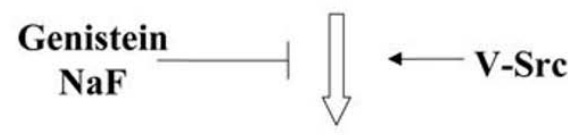

$\Delta$ Phosphorylation

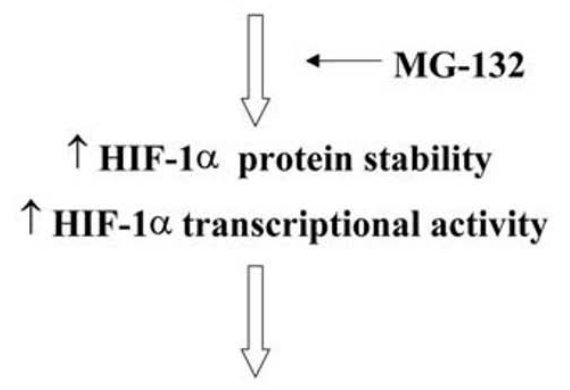

$\uparrow$ Expression of hypoxia-inducible genes

Hypoxia signal transduction. Reduction of cellular $\mathrm{O}_{2}$ concentration ('down' arrow) is associated with redox changes $(\Delta)$ that lead to altered $(\Delta)$ phosphorylation of HIF-1 $\alpha$, which increases its stability and transcriptional activity, resulting in the induction of downstream gene expression. Putative inducers (horizontal arrows) and inhibitors (blocked arrows) of different stages in the proposed pathway are indicated. Genistein is an inhibitor of tyrosine protein kinase and competitive inhibitor of ATP in other protein kinase reactions; $\mathrm{NaF}$ is a nonspecific kinase inhibitor; v-Src is the viral analogue of the mammalian Gcoupled protein kinase; MG-132 is a proteasome complex inhibitor.

a mechanistic stimulus for a graded and adaptive response mediated by HIF-1 $\alpha$. Hypoxia signal transduction is schematized in Fig. 3 and the array of proteins encoded by genes directly controlled by HIF- $1 \alpha$ is given in Table 1 .

The von Hippel-Lindau tumor-suppressor protein

Several major molecular mechanisms that regulate HIF-1 have recently emerged to shed a thorough light on the role of this transcription factor in oxygen sensing [83,84]. The von Hippel-Lindau tumor-suppressor protein ( $p V H L)$ has emerged as a key factor in cellular responses to oxygen availability, being required for the oxygen-dependent proteolysis of the $\alpha$ subunits of HIF (Fig. 4) [83-87]. Mutations in $V H L$ cause a hereditary cancer syndrome associated with dysregulated angiogenesis and upregulation of hypoxia inducible genes [84]. 
Table 1

\begin{tabular}{|c|c|}
\hline Role & Protein \\
\hline \multirow[t]{17}{*}{$\begin{array}{l}\text { Glucose/energy metabolism Cell prolifer- } \\
\text { ation/viability }\end{array}$} & Adenylate kinase 3 \\
\hline & Aldolase a \\
\hline & Aldolase c \\
\hline & Enolase-1 \\
\hline & Glucose transporter 1 \\
\hline & Glucose transporter 3 \\
\hline & $\begin{array}{l}\text { Glyceraldehyde-3-phos- } \\
\text { phate dehydrogenase }\end{array}$ \\
\hline & Hexokinase 1 \\
\hline & Hexokinase 2 \\
\hline & $\begin{array}{l}\text { Insulin-like growth factor } \\
\text { (IGF)-2 }\end{array}$ \\
\hline & $\begin{array}{l}\text { IGF-binding protein } \\
\text { (IGFBP)-1 }\end{array}$ \\
\hline & IGFBP-3 \\
\hline & Lactate dehydrogenase a \\
\hline & Phosphoglycerate kinase 1 \\
\hline & Pyruvate kinase $\mathrm{m}$ \\
\hline & p21 \\
\hline & Transforming growth factor \\
\hline \multirow[t]{4}{*}{ Erythropoiesis Iron metabolism } & Ceruloplasmin \\
\hline & Erythropoietin \\
\hline & Transferring \\
\hline & Transferrin receptor \\
\hline \multirow{8}{*}{$\begin{array}{l}\text { Vascular development/remodelling Vaso- } \\
\text { motor tone }\end{array}$} & Adrenergic receptor \\
\hline & Adrenomedullin \\
\hline & Endothelin-1 \\
\hline & Heme oxygenase-1 \\
\hline & Nitric oxide synthase 2 \\
\hline & $\begin{array}{l}\text { Plasminogen activator } \\
\text { inhibitor } 1\end{array}$ \\
\hline & $\begin{array}{l}\text { Vascular endothelial } \\
\text { growth factor (VEGF) }\end{array}$ \\
\hline & VEGF receptor FLT-1 \\
\hline
\end{tabular}

Recently, Ratcliffe and colleagues unequivocally elaborated on the mechanisms underlying these processes and showed that extracts from VHL-deficient renal carcinoma cells have a defect in HIF- $1 \alpha$ ubiquitination activity, which was complemented by exogenous pVHL [81-84]. This defect was specific for HIF-1 $\alpha$ among a range of substrates tested. Furthermore, HIF- $1 \alpha$ subunits were the only $\mathrm{pVHL}$ associated proteasomal substrates identified by comparison of metabolically labeled anti-pVHL immunoprecipitates from proteosomally inhibited cells and normal cells.

Analysis of $\mathrm{pVHL} / \mathrm{HIF}-1 \alpha$ interactions defined short sequences of conserved residues within the internal transactivation domains of HIF-1 $\alpha$ molecules sufficient for recognition by $\mathrm{pVHL}$. In contrast, while full-length $\mathrm{pVHL}$ and the p19 variant interact with HIF-1 $\alpha$, the association
Figure 4

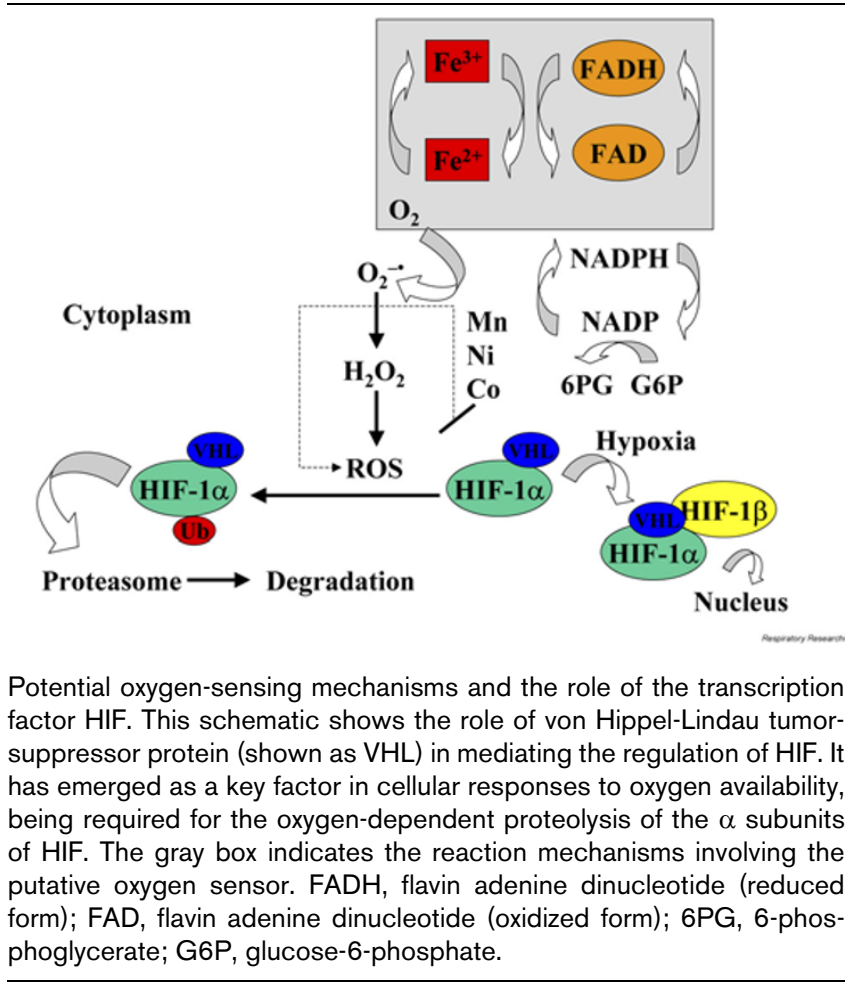

was abrogated by further $\mathrm{N}$-terminal and $\mathrm{C}$-terminal truncations. The interaction was also disrupted by tumor-associated mutations in the $\beta$-domain of $\mathrm{pVHL}$ and loss of interaction was associated with defective HIF-1 $\alpha$ ubiquitination and regulation, defining a mechanism by which these mutations generate a constitutively hypoxic pattern of gene expression promoting angiogenesis [84-87]. These findings clearly indicate that $\mathrm{pVHL}$ regulates HIF- $1 \alpha$ proteolysis by acting as the recognition component of a ubiquitin ligase complex and support a model in which its $\beta$-domain interacts with short recognition sequences in the $\alpha$ subunits. Moreover, in oxygenated and iron-replete cells, HIF- $1 \alpha$ subunits were rapidly destroyed by a mechanism that involved ubiquitination by the $\mathrm{pVHL}$ E3 ligase complex (pVHLE3) [88]. This process was suppressed by hypoxia and iron chelation, allowing transcriptional activation.

\section{HIF- $\alpha$ proline hydroxylation}

Jaakkola and colleagues [88] recently indicated that the interaction between human $\mathrm{pVHL}$ and a specific domain of the HIF- $1 \alpha$ subunit is regulated through hydroxylation of a proline residue (HIF-1 $\alpha$ Pro564) by an enzyme termed by the authors HIF- $\alpha$ prolyl-hydroxylase (HIF-PH). An absolute requirement for oxygen as a cosubstrate and iron as a cofactor suggested that HIF-PH functions directly as a cellular oxygen sensor. Furthermore, Masson et al.[89] recently identified two independent regions within the HIF- $\alpha$ oxygen-dependent degradation domain, which are targeted for ubiquitination by pVHLE3 in a manner dependent upon 
Figure 5

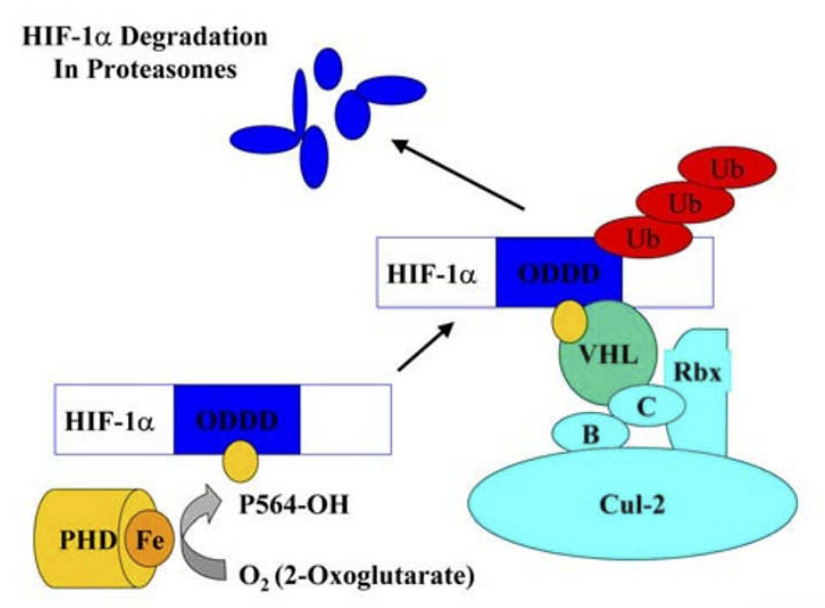

The regulation of HIF by the prolyl hydroxylase (PHD) enzyme, a putative oxygen sensor. The von Hippel-Lindau gene product ( $\mathrm{pVHL}$ ) interacts with HIF- $1 \alpha$ and is required for the destruction of HIF- $1 \alpha$ at the oxygen-dependent degradation domain (ODDD) under normoxic conditions. The HIF-pVHL interaction depends on both oxygen and iron availability (shown as $\mathrm{O}_{2}$ and $\mathrm{Fe}$ ). Furthermore, HIF-1 $\alpha$-pVHL interaction requires enzymatic post-translational hydroxylation of HIF- $1 \alpha$ at a single proline (shown as yellow circle labeled P564-OH). This prolyl hydroxylation also requires, besides oxygen and iron, a citric acid cycle intermediate, 2-oxoglutarate. Together with the HIF-induced activation of glucose- and iron-metabolism genes, hydroxylation creates a tight link between oxygen sensing and cellular control of metabolism. Cul-2, B, C and $\mathrm{Rbx}$ are signaling cofactors associated with $\mathrm{VHL}$ in the regulation of ODDD. Adapted from Jaakkola et al.[88].

prolyl hydroxylation (Fig. 5). In a series of in vitro and in vivo assays, Masson and colleagues demonstrated the independent and nonredundant operation of each site in regulation of the HIF system. Both sites contain a common core motif, but differ both in overall sequence and in the conditions under which they bind to the PVHLE3 ligase complex [89]. The definition of two independent destruction domains implicated a more complex system of pVHL-HIF- $\alpha$ interactions, but reinforced the role of prolyl hydroxylation as an oxygen-dependent destruction signal.

These mechanisms were also reported in lower invertebrates as potential pathways for HIF oxygen sensing. For instance, Epstein and colleagues [90] defined a conserved HIF-pVHL-prolyl hydroxylase pathway in Caenorhabditis elegans and used a genetic approach to identify EGL-9 as a dioxygenase that regulates HIF by prolyl hydroxylation. In mammalian cells, it was shown that the HIF-prolyl hydroxylases were represented by a series of isoforms bearing a conserved 2-histidine-1-carboxylate-iron coordination motif at the catalytic site. Direct modulation of recombinant enzyme activity by graded hypoxia, iron chelation and cobaltous ions mirrored the characteristics of HIF induction in vivo, thereby fulfilling requirements for these HIF-prolyl hy- droxylases to be oxygen sensors that regulate this transcription factor [91-94].

Bruick and McKnight [95] reported that the inappropriate accumulation of HIF caused by forced expression of the HIF- $1 \alpha$ subunit under normoxic conditions was attenuated by co-expression of HIF-PH. Suppression of HIF-PH in cultured Drosophila melanogaster cells by RNA interference resulted in elevated expression of a hypoxia-inducible gene (encoding lactate dehydrogenase) under normoxic conditions, indicating that HIF-PH is an essential component of the pathway through which cells sense oxygen. In complement with the aforementioned observations, Lando and colleagues [96] demonstrated that the hypoxic induction of the $\mathrm{C}$-terminal transactivation domain (CAD) of HIF occurs through abrogation of hydroxylation of a conserved asparagine in the CAD. Inhibitors of $\mathrm{Fe}^{2+}$ - and 2-oxoglutaratedependent dioxygenases prevented hydroxylation of the asparagine, thus allowing the CAD to interact with the p300 transcription co-activator. Replacement of the conserved asparagine by alanine resulted in constitutive p300 interaction and strong transcriptional activity. The full induction of HIF, therefore, might rely on the abrogation of both proline and asparagine hydroxylation. During normoxia, hydroxylation of these residues occurs at the oxygen-dependent degradation domain and CAD, respectively.

\section{HIF-2 $\alpha$ and HIF-3 $\alpha$}

Recently, two oxygen-sensitive cousins of HIF-1 have been identified, characterized and cloned. HIF-2 and HIF-3 are two closely related protein complexes that are oxygenresponsive. The cDNAs of three HIF $\alpha$-subunits were cloned from RNA of primary rat hepatocytes by reverse transcriptase PCR [97]. All three cDNAs encoded functionally active proteins, of 825,874 and 662 amino acids, respectively. After transfection, they were able to activate luciferase activity of a luciferase gene construct containing three HIF-responsive elements. The mRNAs of the rat HIF $\alpha$-subunits were expressed predominantly in the perivenous zone of rat liver tissue; the nuclear HIF- $\alpha$ proteins, however, did not appear to be zonated [97]. Furthermore, HIFs locate to HIF-binding sites (HBSs) within the HREs of oxygen-regulated genes $[98,99]$. Whereas HIF- $1 \alpha$ is generally expressed ubiquitously, HIF- $2 \alpha$ (EPAS) is found primarily in the endothelium, similar to endothelin-1 (ET-1) and fms-like tyrosine kinase-1 (Flt-1), the expression of which is controlled by HREs.

Camenisch and colleagues [100] identified a unique sequence alteration in both ET-1 and Flt-1 HBSs not found in other HIF-1 target genes, implying that these HBSs might cause binding of HIF-2 rather than HIF-1. Electrophoretic mobility shift assays showed HIF-1 and HIF-2 DNA complex formation with the unique ET-1 HBS to be about equal. Both DNA-binding and hypoxic activation of reporter genes 
using the ET-1 HBS was decreased compared with those for transferrin and erythropoietin HBSs. The Flt-1 HBS, in addition, was nonfunctional when assayed in isolation, suggesting that additional factors are required for hypoxic upregulation via the reported Flt-1 HRE [100]. Interestingly, HIF-1 activity could be restored fully by point-mutating the ET-1 (but not the Flt-1) HBS, suggesting that the wild-type ET-1 HBS attenuates the full hypoxic response known from other oxygen-regulated genes [100-102].

\section{Oxygen homeostasis and NF- $\kappa B$ regulation}

$\mathrm{NF}-\mathrm{KB}$ is an important and widely investigated dimeric transcription factor that is a major participant in signaling pathways governing cellular responses to environmental stresses $[13,14,19,54,55,58,103,104]$. NF-кB is involved in the regulation of a large number of genes that control various aspects of the immune and inflammatory response. It is activated by a variety of stimuli ranging from cytokines, to various forms of radiation, to oxidative stress (such as exposure to $\mathrm{H}_{2} \mathrm{O}_{2}$ ). Recent studies have advanced our understanding of the signal transduction pathway leading to NF$\kappa B$ activation by cytokines and will provide insights for the mechanism by which NF- $\mathrm{KB}$ is regulated by oxidative stress. An important question that is yet to be answered is whether ROS play a physiological role in NF- $\mathrm{KB}$ activation.

First identified as a factor which regulates the expression of the immunoglobulin $\kappa$ light chains in B lymphocytes [57] $\mathrm{NF}-\mathrm{KB}$ is also recognized as a sequence-specific transcription factor involved in the activation of an exceptionally large number of genes in response to inflammation, viral and bacterial infections, and other stressful situations requiring rapid reprogramming of gene expression, such as oxidative challenge [54,55]. In unstimulated cells under resting conditions (inactive state), NF- $\mathrm{kB}$ exists as homodimers or heterodimers of members of the Rel family $[55,56,103,104]$. The dimers of NF- $\mathrm{kB}$ are sequestered in the cytosol through noncovalent interactions with inhibitory proteins termed IKBs $[54,55,103,104]$. The translocation and activation of NF- $\mathrm{KB}$ in response to various stimuli, such as cytokines (IL-1 and TNF- $\alpha$ ), microbial agents (lipopolysaccharide-endotoxin), oxidative challenge (ROS) and irradiation (UV and $\gamma$-rays), are sequentially organized at the molecular level $[54,55,104]$. NF- $\kappa B$ activation occurs through the signal-induced phosphorylation of a multisubunit upstream kinase, termed IKB kinase, by NF- $\kappa B$ inducing kinase [103-105]. Stimulation leads to rapid phosphorylation of $1 \kappa B$, thereby marking it for ubiquitinylation and ultimately proteolytic degradation. IאB degradation exposes the nuclear localization signal on NF- $\kappa B$, thus allowing the nuclear translocation of the subunit and activation of the transcription of its target genes (Fig. 6) [54,55]. The array of proteins encoded by genes directly controlled by NF-kB is given in Table 2 .
Figure 6

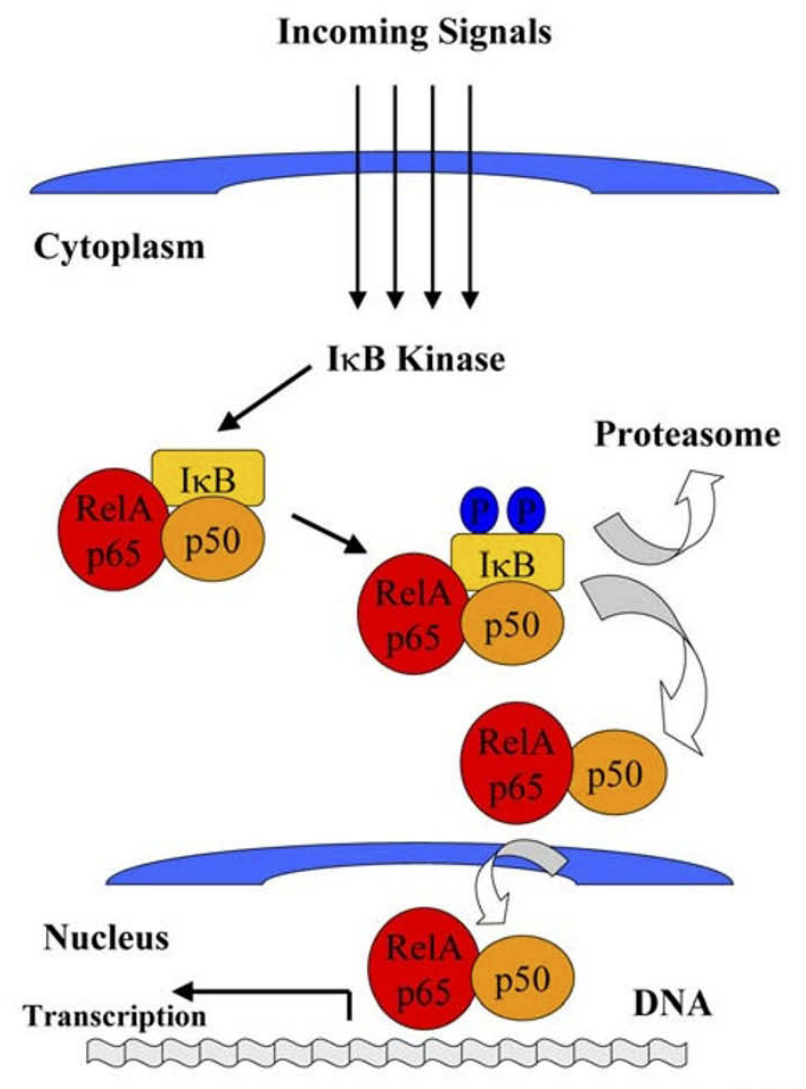

Rel/NF- $\kappa B$ signal transduction. Various extracellular signals converge

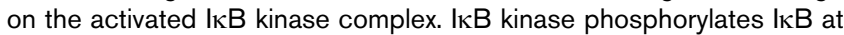
two N-terminal serines; phosphorylation signals IKB for ubiquitination and proteolysis in the proteasome. The NF-kB (p50-RelA in this case) released in this way enters the nucleus and activates gene expression.

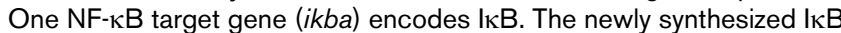
can enter the nucleus, pull NF-kB off DNA, and export NF-kB back to its resting state in the cytoplasm. Thick lines indicate the activating pathway; thin lines indicate the inactivating pathway.

IKB-independent pathways, however, have recently been recognized as alternative factors that regulate the activation of NF-kB. As an example, direct phosphorylation of RelA (p65), the major transactivating member of the $\mathrm{kB}$ family $[14,19,54,55,103]$ has been shown to regulate NF$\kappa B$ activation in one of two of its transactivation domains [106]. A further mechanism was revealed for NF- $\mathrm{KB}$ regulation with the discovery of transcription factor-IIB/D (TFIIB/D) and TATA-binding protein (TBP), recognized as two important regulators of NF- $\mathrm{BB}$ transcriptional activity. The dominant-negative form of the mitogen-activated protein kinase (MAPKp38) expression vector abrogated the interaction of TF-IID/TBP with a co-transfected His-p65 fusion protein, and selective inhibition of MAPKp38 by SB203580 down-regulated TF-IID/TBP in vitro[106]. Finally, modulation of intracellular redox equilibrium constitutes a potential mechanism that can manipulate and dictate the lo- 
calization and activation of NF- $\mathrm{B}$ $[2,3,13,14,26,54,55,103-106]$. Hyperoxia and other stress conditions mediating signal-transduction pathways involving NF- $\kappa \mathrm{B}$ are depicted in a schematized model shown in Fig. 7.

\section{Redox regulation of oxygen-sensitive transcrip- tion factors}

The major determinant of the redox status in mammalian cells is glutathione ( $\mathrm{L}-\gamma$-glutamyl-L-cysteinyl-glycine), a tripeptide thiol $[14,18,47-50,107]$. This ubiquitous nonessential sulfhydryl amino acid plays a major role in maintaining intracellular redox equilibrium and in regulating cellular defenses augmented by oxidative stress. Synthesized by the action of the rate-limiting enzyme $\gamma$-glutamylcysteine synthetase $[47-50,107,108]$ glutathione uniquely provides a functional cysteinyl moiety that is responsible for many of its diverse properties.

Glutathione participation in the physiology of cellular metabolism reflects the importance of this molecule in intracellular functions. First, glutathione is involved in the detoxification of highly reactive peroxides $(\mathrm{ROOH})$ by conjugation of electrophiles and metals through the glutathione-peroxidase coupled reaction, thus acting as an antioxidant (Fig. 1). For example, endogenously produced radicals such as $\mathrm{H}_{2} \mathrm{O}_{2}$ are effectively reduced by the selenium-dependent glutathione peroxidase in the presence of glutathione as a substrate. During this reaction, glutathione is converted into oxidized disulfide glutathione (GSSG), which is recycled back to two molecules of glutathione by GSSG reductase at the expense of NADPH/H+, thus forming what is known a redox cycle (Fig. 1). Second, glutathione participates in the maintenance of intracellular protein integrity by reducing their disulfide linkages and regulating their synthesis, thereby acting as an important regulator of cellular sulfhydryl status and redox equilibrium. Third, glutathione governs signaling pathways as an immunopharmacological reducing thiol; it also facilitates membrane trafficking of reactive chemicals and, in some cases, augments the formation of essential biological mediators. Fourth, glutathione regulates the expression and activation of redox-sensitive transcription factors, whose upregulation is a key component of the cellular pathways activated in stress-evoked responses. The restitution of redox equilibrium in the face of an oxidative challenge, therefore, requires an adaptive cross-talk between signaling pathways sensing variations in $\mathrm{pO}_{2}$ and genetically regulated transcription factors [2,3,16-18,26,51]. As such, glutathioneassociated metabolism is crucial for providing an equilibrium interface between oxidative stress and adaptive responses of cytoprotection [13,14,19,47-50,107].

\section{Redox regulation of HIF-1 $\alpha$}

Antioxidant/pro-oxidant equilibrium is likely to regulate HIF$1 \alpha$ redox sensitivity $[13,14,51,73,109-111]$. For instance,
Table 2

The array of proteins encoded by genes directly controlled by NF- $K B$

\begin{tabular}{|c|c|}
\hline Protein type & Protein \\
\hline Cytokines/growth factors & $\begin{array}{l}\text { IL-1 } \alpha \\
\text { IL-1 } \beta \\
\text { IL-2 } \\
\text { IL-3 } \\
\text { IL-6 } \\
\text { IL-8 } \\
\text { IL-12 } \\
\text { TNF- } \alpha \\
\text { Lymphotoxin- } \alpha \\
\text { Interferon- } \beta \\
\text { Granulocyte Colony-Stimulating } \\
\text { Factor } \\
\text { Macrophage Colony-Stimulating } \\
\text { Factor } \\
\text { Granulocyte-Macrophage Colony- } \\
\text { Stimulating Factor }\end{array}$ \\
\hline Cytokine receptors & IL-2 receptor $\alpha$ chain \\
\hline Stress proteins & $\begin{array}{l}\text { Serum amyloid A protein } \\
\text { Complement factors } B, C 3 \text { and } C 4 \\
\alpha_{1} \text {-acid glycoprotein }\end{array}$ \\
\hline Adhesion molecules & $\begin{array}{l}\text { Intracellular adhesion molecule-1 } \\
\text { Vascular cell adhesion molecule-1 } \\
\text { Mucosal addressin cell adhesion mole- } \\
\text { cule-1 } \\
\text { E-selectin }\end{array}$ \\
\hline Immunoregulatory mole- & Immunoglobulin $\kappa$ light chain \\
\hline & $\begin{array}{l}\text { MHC class I and II } \\
\text { T-cell receptor } \alpha \text { and } \beta \\
\beta_{2} \text {-Microglobulin } \\
\text { Invariant chain } \\
\text { Transporter associated with antigen } \\
\text { processing } \\
\text { Proteasome subunit } \\
\text { Inducible nitric oxide synthase } \\
\text { Inhibitory } \kappa B \\
\text { p53 }\end{array}$ \\
\hline
\end{tabular}

the cysteine residue in the CAD has been shown to be redox-sensitive, thereby affecting its interaction with CREBbinding protein/p300 co-activators. This interaction is directly regulated by redox factor- 1 and thioredoxin $[109,110]$. HIF-1 $\alpha$ ubiquitination and degradation by the proteasome system under normoxic conditions are also regulated by redox modifications of the protein $[52,53,82,111]$. Furthermore, selective inhibition of $\gamma$ glutamylcysteine synthetase (which results in glutathione depletion) in the alveolar perinatal epithelium abrogated hypoxia-induced nuclear localization, stabilization and activation of HIF-1 $\alpha$ [13,14]. It appears, therefore, that maintenance of glutathione equilibrium (and by inference, 


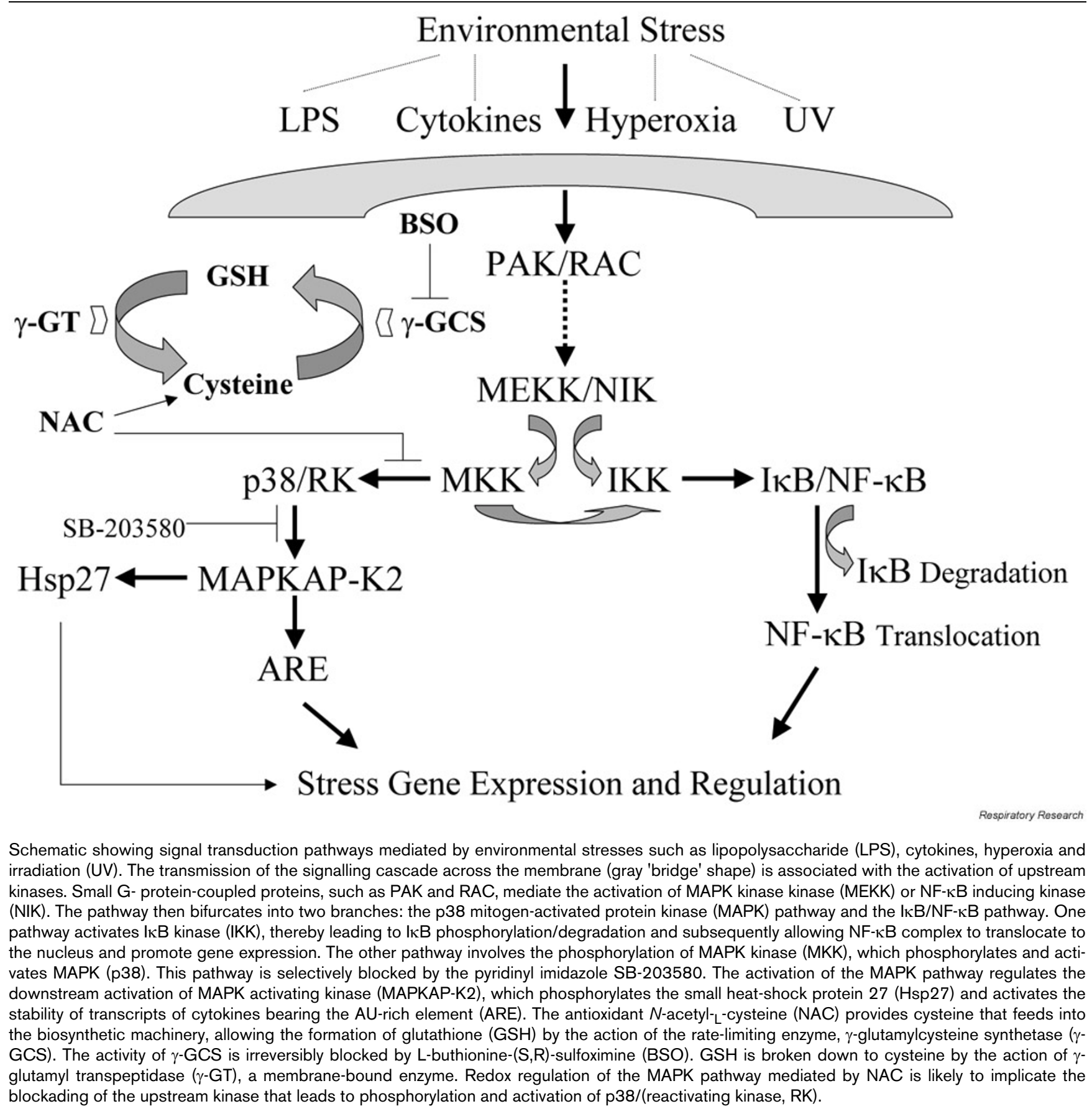

the shuttling between reduction and oxidation states) is a prerequisite for HIF-1 $\alpha$ stabilization [82,109].

This assumption is reinforced by the observation that $\mathrm{N}$ acetyl-L-cysteine (NAC, an antioxidant thiol and a precursor for L-cysteine, the rate-limiting amino acid in the biosynthesis of glutathione $[14,17,112]$ ) imposes a reducing environment, thereby protracting HIF- $1 \alpha$ stability in the cytosol and subsequently favoring its translocation and activation
$[13,14,53,54,82,111]$. On the other hand, imposing an oxidizing environment through the rapid accumulation of GSSG in the nucleus adversely affects HIF- $1 \alpha$ activation $[13,14]$. PDTC is a nonthiol antioxidant that affects redox potential by scavenging radical species (a reduction property) and directly oxidizing glutathione and related thiols (an oxidation property) $[14,79,113]$. PDTC favors a GSSG/ glutathione equilibrium and subsequent stabilization of HIF$1 \alpha$ protein, but fails to induce its activation. This effect is 


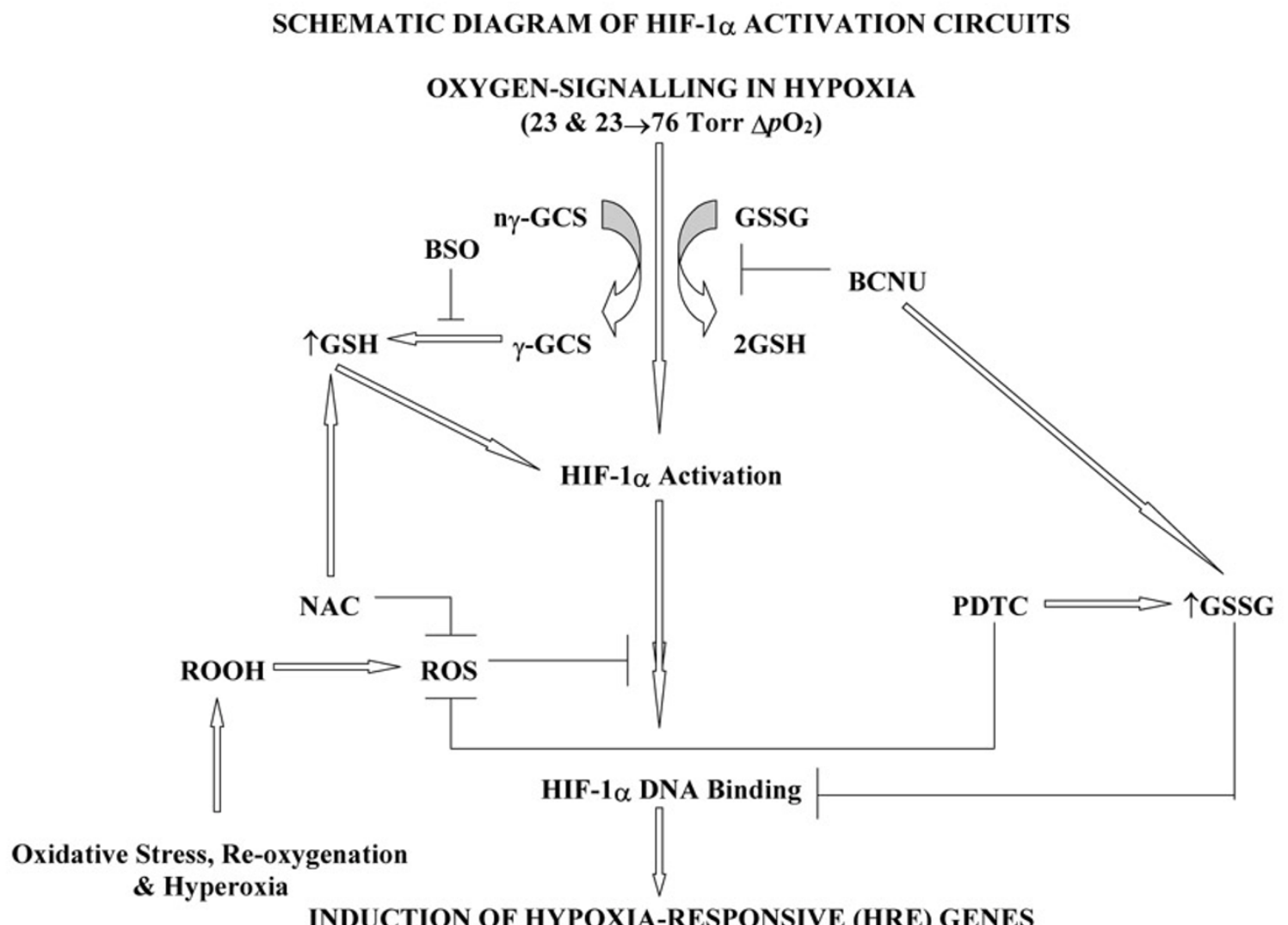

Respiratory Research

Schematic diagram of HIF-1 $\alpha$ activation circuits and oxygen-signaling mechanisms in hypoxia. The reduction of oxidized glutathione (GSSG) forms reduced glutathione (2GSH), capable of inducing HIF-1 $\alpha$ activation. GSSG recycling to GSH is blocked by 1,3-bis-(2-chloroethyl)-1-nitrosourea (BCNU), a specific glutathione reductase inhibitor, thus increasing intracellular [GSSG], a potent inhibitor of DNA binding. In oxidative stress, $\gamma$ glutamylcysteine synthetase is transformed from the native, inactive form ( $\mathrm{n} \gamma$-GCS) to the active form ( $\gamma$-GCS), which increases de novo synthesis of GSH. This pathway is blocked by $L$-buthionine- $(S, R)$-sulfoximine (BSO), an irreversible inhibitor of $\gamma$-GCS, thus affecting HIF-1 $\alpha$ activation. Reactive oxygen species (ROS), derived from oxygen metabolites (ROOH), tend to block the activation of HIF-1 $\alpha$. N-acetyl- $\mathrm{L}^{-}$cysteine (NAC), an antioxidant, releases this inhibitory effect by scavenging ROS. NAC, in addition, is a major precursor of GSH, a thiol antioxidant, thereby elevating [GSH] ( $\uparrow$ GSH) and inducing HIF-1 $\alpha$ activation. Pyrrolidine dithiocarbamate (PDTC) is an antioxidant; although it possesses ROS-scavenging properties, its ability to activate HIF-1 $\alpha$ under reducing conditions is not established. PDTC (as a pro-oxidant), like other dithiocarbamates, lowers the GSH/GSSG ratio by oxidizing GSH. The elevated [GSSG] ( $\uparrow$ GSSG) has the potential to block HIF-1 $\alpha$ activation. Upon HIF- $1 \alpha$ binding to the hypoxia response element (HRE), hypoxia-responsive genes are upregulated.

ostensibly due to the generation of thiyl radicals and thiuram disulfides resulting from PDTC antioxidant reactions, thus leading to oxidation of glutathione [13,14,111]. It is very likely, therefore, that HIF-1 $\alpha$ 's oxygen responsiveness resides over a permissive range of antioxidant buffering capacities, with the demonstration that the antioxidant/ pro-oxidant equilibrium effectively uncouples HIF- $1 \alpha$ activity from the normal pattern observed in response to variations in $\mathrm{pO}_{2}$ in the alveolar epithelium $[13,14,82]$. Redox- mediated pathways regulating HIF- $1 \alpha$ transduction mechanisms are shown in Fig. 8.

\section{Redox regulation of $\mathrm{NF}-\kappa \mathrm{B}$}

Redox regulation of NF- $\kappa \mathrm{B}$ seems to be compartmentalized $[13,14,19,54,55,62,113,114]$. Whereas an oxidizing signal is required for the stabilization and translocation of NF$\kappa \mathrm{B}$ subunits, intriguingly, a reduced environment is critical for an optimum DNA-binding activity and transactivity $[14,54,55,113,114]$. Recent evidence suggests that NF- 


\section{SCHEMATIC DIAGRAM OF NFKB ACTIVATION CIRCUITS}

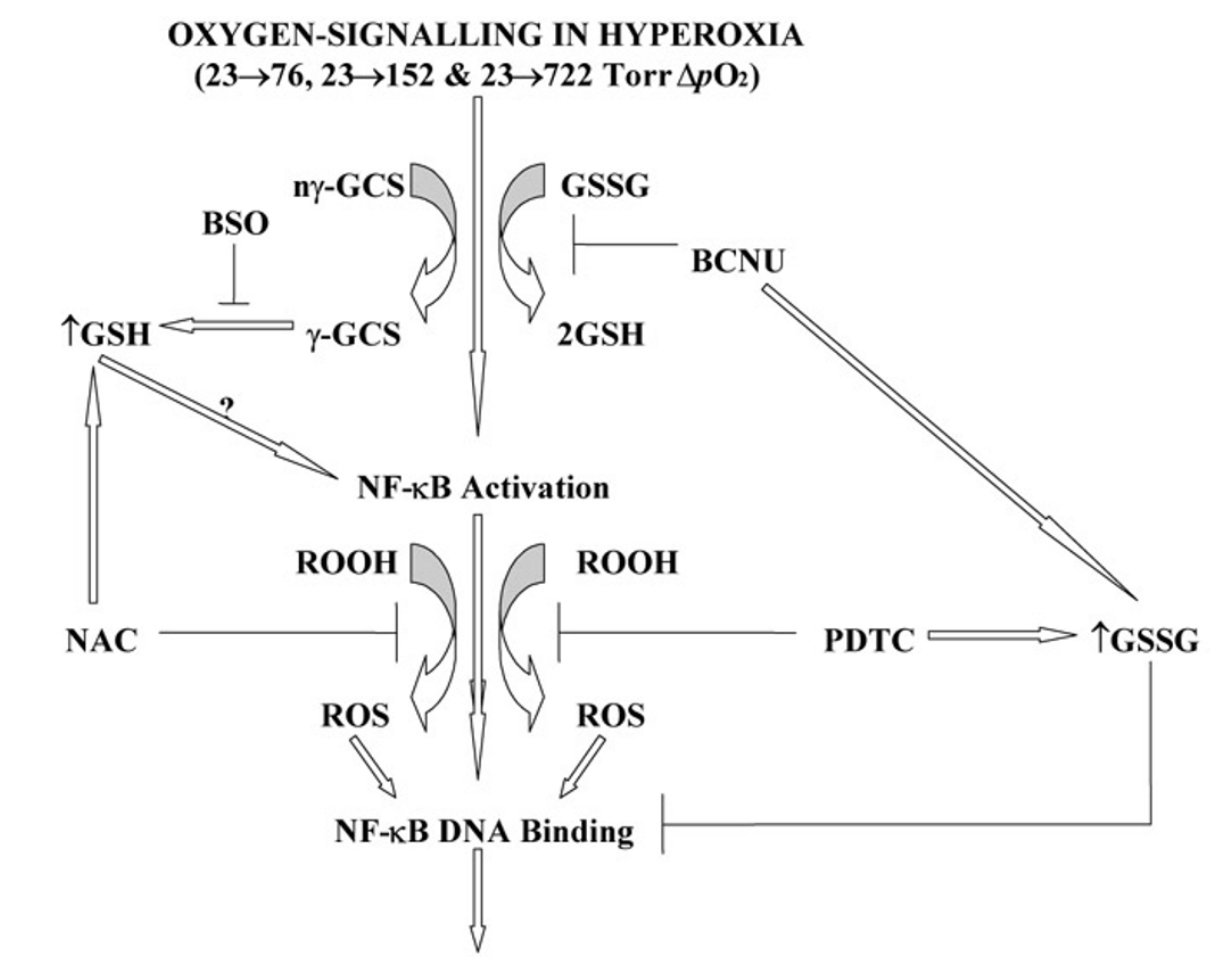

INDUCTION OF OXIDATIVE STRESS-RESPONSIVE GENES

[AQ27] Schematic diagram of NF-kB activation circuits and oxygen-signaling mechanisms in hyperoxia. Blocking reduction of oxidized glutathione (GSSG) to GSH, by 1,3-bis-(2-chloroethyl)-1-nitrosourea (BCNU), leads to increasing intracellular stores of GSSG, a potent inhibitor of NF-kB transcription factor DNA binding. The pathway leading to the formation of GSH by the action of $\gamma$-glutamylcysteine synthetase $\left(\gamma\right.$-GCS) is blocked by ${ }^{-}$ buthionine-(S,R)-sulfoximine (BSO), inducing an irreversible inhibition of NF-kB activation. ROS are key components of the pathways leading to the activation of NF-KB, whose binding activity is obliterated by $N$-acetyl- - -cysteine (NAC) and pyrrolidine dithiocarbamate (PDTC), potent scavengers of ROS. Although NAC elevates [GSH], it is unknown whether this mechanism induces NF- $\kappa B$ activation independently from the antioxidant effects of this inhibitor. PDTC elevates GSSG concentration by GSH oxidation, a pro-oxidant effect characteristic of dithiocarbamates, thereby mediating

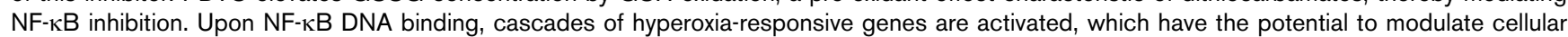
response to oxidative injury.

$\kappa \mathrm{B}$ plays a critical role in the early events controlling the molecular response to ROS $[54,55,58,103]$. It has been shown, for example, that the activation of NF- $\mathrm{KB}$ by a variety of agents can be blocked by NAC, suggesting that the production of ROS may act as a common pathway for a diverse range of stimuli $[13,14,54,55,58,62,101,103,114-$ $116]$. In addition, the inhibitory effects of PDTC suggest post-translational instability and interference with the capacity of NF-KB to bind DNA $[54,55,62,103,104]$. This is further supported by the observation that phosphorylation of $\mathrm{I} K \mathrm{~B}$ at specific serine residues can be inhibited by dithiocarbamates, pointing to the possibility that NF-KB translo- cation and subsequent activation is mediated by ROS, which might induce a cytosolic kinase activity $[54,55,103,104]$.

There is another assumption that GSSG-mediated inhibition of NF- $\kappa B$ implicates the formation of an inactive NF$\kappa \mathrm{B} /$ disulfide complex, thereby inhibiting DNA binding activity $[14,16-18,54,55,62,114-116]$. Although oxidizing conditions are necessary in the cytosol, to allow optimum translocation and dissociation of NF- $\mathrm{KB}$ from inhibitory $\mathrm{I}_{\mathrm{K}} \mathrm{B}$ (resulting in activation of NF- $\mathrm{KB}$ ), NF- $\mathrm{KB}$ must be maintained in a reduced state in the nucleus for activation to oc- 
cur $\quad[13,14,16-19,54,55,58,62,103,104,114-116]$. Redox-mediated pathways regulating NF- $\kappa \mathrm{B}$ transduction mechanisms are shown in Fig. 9.

\section{Regulation of apoptosis signaling pathways: morphological, biochemical and redox/ROS aspects}

In the past few decades since the term apoptosis was coined $[117,118]$ a vast quantity of work has been performed in search of the cause of the phenomenon to which it originally alluded. It became certain that some cells were genetically programmed, or destined, for death during the normal development of multicellular organisms [118-126]. Thus the general model is one of intercellular signaling molecules playing on intracellular effector systems that balance the individual cell's progress to either life (survival) or death (apoptosis) [119-126]. Apoptosis, first identified as "shrinkage necrosis" [117] was originally observed in mature human/vertebrate tissues as a stochastic loss of cells that showed distinctive histopathic morphology and induced a minor inflammatory response [118-126]. Simply, it was argued that the key tenets of this model state that there is a universal genetic program that governs cell death at different stages of development, that a variety of stimuli can elicit or activate this program, and that, even though many transduction mechanisms are involved, eventually apoptosis requires activation of a downstream convergent, final pathway [119-126].

\section{The distinct forms of cell death: morphological aspects}

At least two distinct forms of death are known by which cells undergo death: the well-characterized, and usually rapid, necrotic tissue damage induced by trauma and noxious stimuli, and the more protracted and morphologically distinct form of cell death that has been termed apoptosis [117-126].

Apoptosis is characterized by an ordered series of events that take place over a longer period of time than events during necrotic cell death. In apoptosis, cells often shrink, dissociate from surrounding cells and undergo cytoplasmic membrane blebbing, a process in which their chromosomes rapidly condense and aggregate around the nuclear periphery and small apoptotic bodies are formed. During apoptosis cellular organelles retain their definition for a long time; the nucleus in particular displays a distinctive pattern of heterochromatization and eventual fragmentation. In many (but not all) apoptotic cells, specific nucleases cleave the DNA of the condensed chromosomes, thereby producing a characteristic 'ladder' [123-127].

Necrotic cell death, on the other hand, is relatively quick and violent, characterized by the swelling of the cytoplasm, the rupturing of cell membranes, the dilation of the mitochondria and the disintegration of subcellular and nuclear components. Necrosis may be considered to be analogous to random acts of violence that culminate in murder, whereas apoptosis is more appropriately referred to as cellular suicide. The cell initiates apoptotic death when it senses that its environment of physical state has been vigorously compromised; this is, indeed, the ultimate self-sacrifice [117-127].

\section{The biochemistry of cell death: molecular aspects}

If there is simple dichotomy in the modes of cell death, perhaps there is more than one basic genetic program for death and more than one final common pathway (Fig. 10A). Perhaps some ligand-induced cell death results from confused or inappropriate regulation of gene expression rather than from turning on preset genetic programs [119-126]. Studies of C. elegans development, for example, have contributed significantly to the biomolecular understanding of cell death $[119,120]$. Genetic analysis has led to the identification of the cellular genes required for programmed cell death during their development. The isolation and molecular characterization of C. elegans death (ced) genes demonstrated that ced-3 gene is homologous to the gene encoding mammalian IL-1 $\beta$-converting enzyme (ICE; caspase-1) [126-129]. ICE was originally isolated from mammalian cells as an enzyme essential for the proper processing and biological activation of pro-IL-1 $\beta$, a cytokine involved in mediating cellular inflammatory processes $[36,40,42-46]$. The expression of ced-3/ICE rapidly induces apoptosis, demonstrating that this gene encodes a cysteine protease essential for programmed cell death [127-129].

Many of the genes encoding ICE-like proteases, henceforth referred to as caspases, were isolated by molecular cloning. The term caspase is based on a common nomenclature universally adopted: 'c' reflects a cysteine protease mechanism, and 'aspase' refers to the ability of these proteases to cleave a protein following an aspartic acid residue [127129]. Many of these caspases contain a conserved sequence, $\mathrm{QAC}(\mathrm{R} / \mathrm{Q}) \mathrm{G}$, required for the catalytic activity of these enzymes [127-130]. The activation of the caspase proteases has been linked to the aggregation of cell surface receptors, either when receptor-sensitive target cells are exposed to the appropriate ligand, or when the receptors self-aggregate in response to their high cell-surface density. A functional caspase, therefore, can be generated following receptor oligomerization by autocatalysis or by the action of another alerted caspase. Recent evidence suggested that caspases regulate the process of apoptosis by regulating additional cellular processes, such as the progression through the well-defined cell cycle and its regulators [126-130].

\section{The molecular signaling factors regulating apoptosis}

As noted, multicellular organisms eliminate redundant, damaged, or infected cells by a stereotypic program of cell 


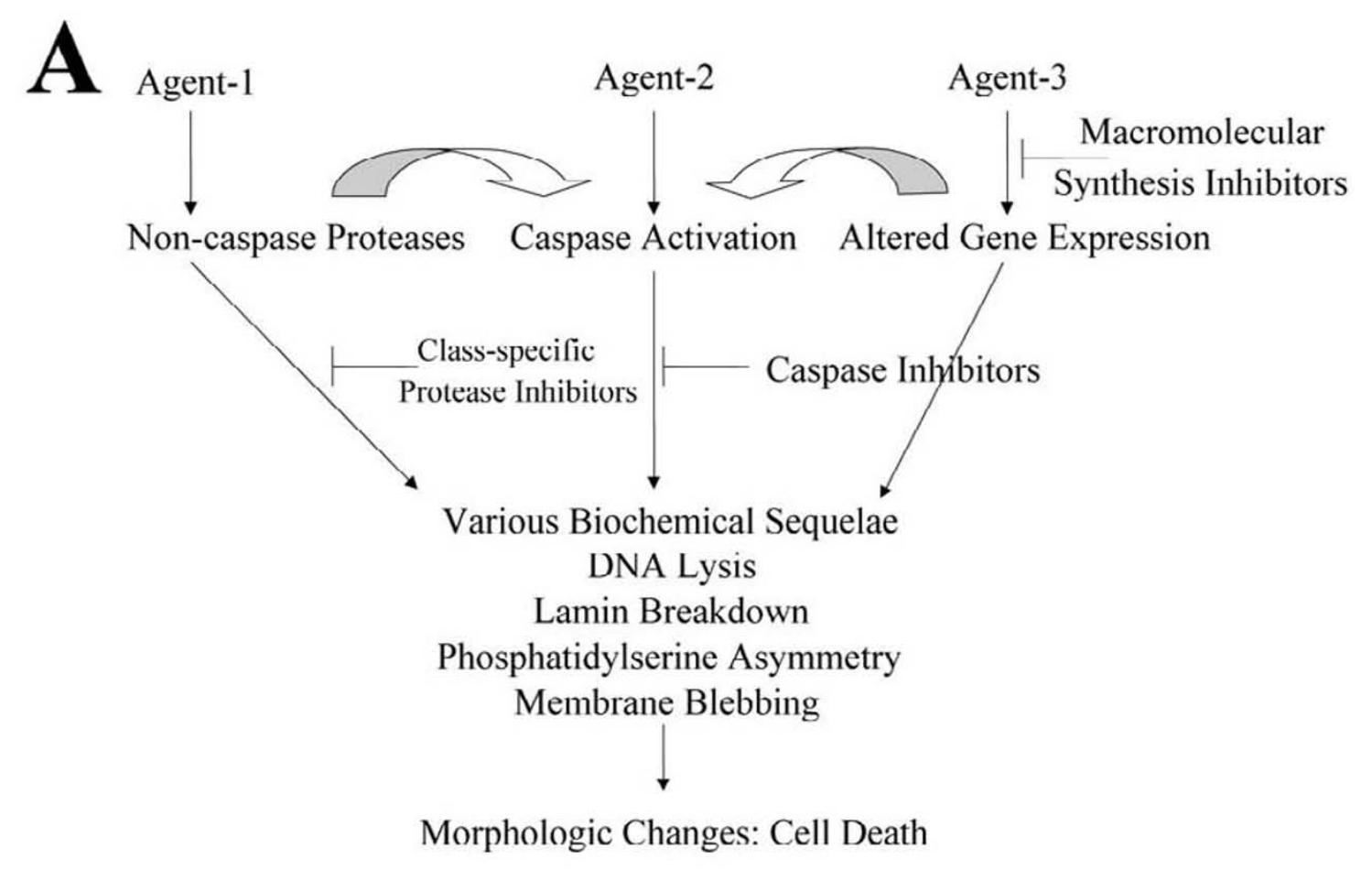

B

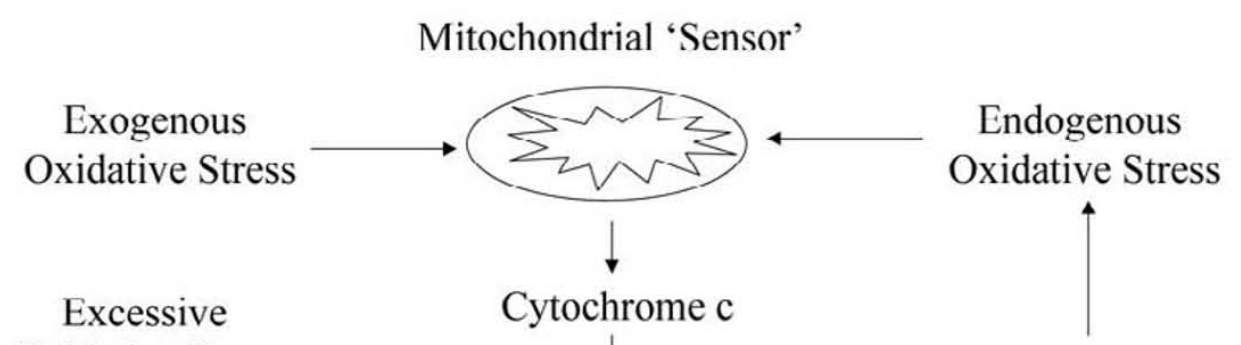

Oxidative Stress

Antioxidants GSH Precursors

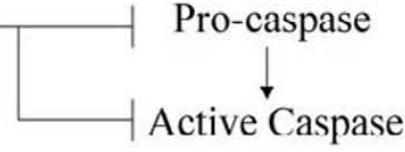

External Stimulus

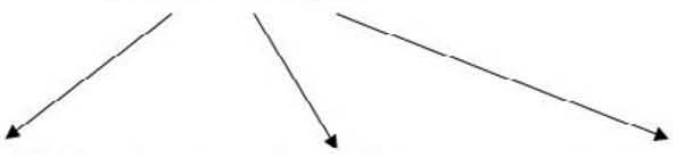

$\rightarrow$ Phosphatidylserine Nuclear Changes Membrane and

Asymmetry DNA Damage Mitochondrial

Changes 
suicide. The first mammalian regulator of apoptosis emerged when $b c /-2$, the gene activated by chromosome translocation in human follicular lymphoma [131] was unexpectedly found to permit the survival of cytokine-dependent hematopoietic cells, in a quiescent state in the absence of exogenous cytokine [132]. Ced-9 of C. elegans and the mammalian Bcl-2 proved to be functional and structural homologues and their survival function is opposed either by close relatives, like Bax, or by distant cousins such as the mammalian proteins Bik, or Nbk, and nematode Egl-1 [127-132]. All Bcl-2 family members possess at least one of four conserved motifs known as Bcl-2 homology domains $(\mathrm{BH}-1,-2,-3$, and -4$)$. Most prosurvival family members, which can inhibit apoptosis in the face of a wide variety of cytotoxic insults, contain at least $\mathrm{BH}-1$ and $\mathrm{BH}-2$, and those most similar in structure to $\mathrm{Bcl}-2$ have all four $\mathrm{BH}$ domains [127-132].

Pro-apoptotic and anti-apoptotic family members can heterodimerize and seemingly titrate one another's function, suggesting that their relative concentrations may act as a rheostat for the suicide programs [133]. Bcl-2 resides on the cytoplasmic face of the mitochondrial outer membrane, endoplasmic reticulum and nuclear envelope, and may register damage to these compartments and affect their behavior, possibly by modifying the flux of small molecules and proteins [133]. On the other hand, Bax is cytosolic before an apoptotic stimulus, even though it bears a hydrophobic domain (like most other family members) [133]. Biochemical evidence suggested that the prosurvival proteins might function by directly inhibiting the activity of caspases, directly or indirectly preventing the release of cytochrome $c$ from the mitochondria. Along with ATP, this may facilitate structural changes in the procaspase domain, allowing its cleavage and activation [127-133]. Bax, Baxlike proteins and the antisurvival proteins may promote apoptosis by cleaving and activating caspases, but also can initiate caspase-independent death via channel-forming activity, which could promote the mitochondrial permeability transition or puncture the mitochondrial outer membrane [134-141].

\section{Oxygen and redox regulation of apoptosis: Involvement of transcription factors}

ROS are generated in all aerobic cells during normal mitochondrial respiration, are used by specialized phagocytic cells to destroy invading pathogens and are byproducts of the intracellular metabolism of toxic drugs and their environmental metabolites $[2,3,16-18,26]$. Incubating cells, for instance, with exogenous oxidants, free radicals, or added redox-active compounds has been shown to trigger the apoptotic process [142-155]. It has been hypothesized that the oxidation of cellular molecules could trigger a general protection alert system, and these sensors, in turn, detect and assess the damage, subsequently activating the apop- totic machinery. A classic example of this model is p53mediated detection of DNA damage [156-159]. Alternatively, low-level oxidative stress is known to activate different protein cascades and transcription factors, such as AP1 , HIF-1 $\alpha$, and NF-KB [2,3,16-18,26,51-55]. In addition, the ability of NO to rapidly react with the heme group of guanylate cyclase has been used as a message in activating downstream apoptotic cellular pathways $[150,155]$.

Recent studies have focused on the role of $\mathrm{H}_{2} \mathrm{O}_{2}$ in regulating apoptosis in several cell models. $\mathrm{H}_{2} \mathrm{O}_{2}$ is an oxidant that has been shown to trigger caspase activation and subsequent apoptosis. $\mathrm{H}_{2} \mathrm{O}_{2}$-mediated caspase activation is dependent on the release of cytochrome $c$ from the mitochondria, suggesting a key role for $\mathrm{H}_{2} \mathrm{O}_{2}$ in mitochondrial permeability and leakage $[142,144,147,149,150,153]$.

The importance of dissecting the pathway from oxidative stress/redox signaling to apoptosis is not restricted to models in which cells are exposed to exogenous oxidants. Schematized pathways of apoptosis in the alveolar model and in the developing lung are given in Fig. 11. Intracellular oxidant production has been detected in cells incubated with a wide range of seemingly independent apoptotic agents, and some of these changes have been suggested to occur sufficiently early to be intricately involved in the activation of apoptosis [160]. A recent example is p53-mediated apoptosis, which has been proposed to occur through the increased transcription of pro-oxidant factors, thereby leading to caspase activation and apoptosis [156-159]. Interestingly, antioxidants and glutathione precursors conferred a protective effect against ROS-mediated injury and subsequent apoptosis, implicating a critical role for ROS in initiating the death machinery [142-154].

It is becoming apparent, therefore, that the redox status of a cell can have complex and multilayered effects on apoptosis (Fig. 10B) [161]. It has been postulated that the mitochondria could be the principle sensors and that the release of mitochondrial factors such as cytochrome $c$ is the critical event leading to caspase activation, and hence propagation of apoptosis [142-155]. The effectors of apoptosis, in particular the caspases, are redox-sensitive, and the cell must maintain a strict reducing environment for these effectors to function. By reasoning, therefore, it has been hypothesized that apoptosis cannot occur in cells subjected to excessive oxidative stress [144-161]. The ability of oxidants to inhibit caspase function need not be incompatible with oxidant-dependent caspase activation. First, low levels of oxidants appear sufficient for optimal caspase activation, suggesting specific signaling pathways rather than widespread oxidation. Second, the observed ability of cells to repair or replace oxidized caspases indicates that the full complement of apoptotic effector molecules can be regained at some time after the initial oxidative 


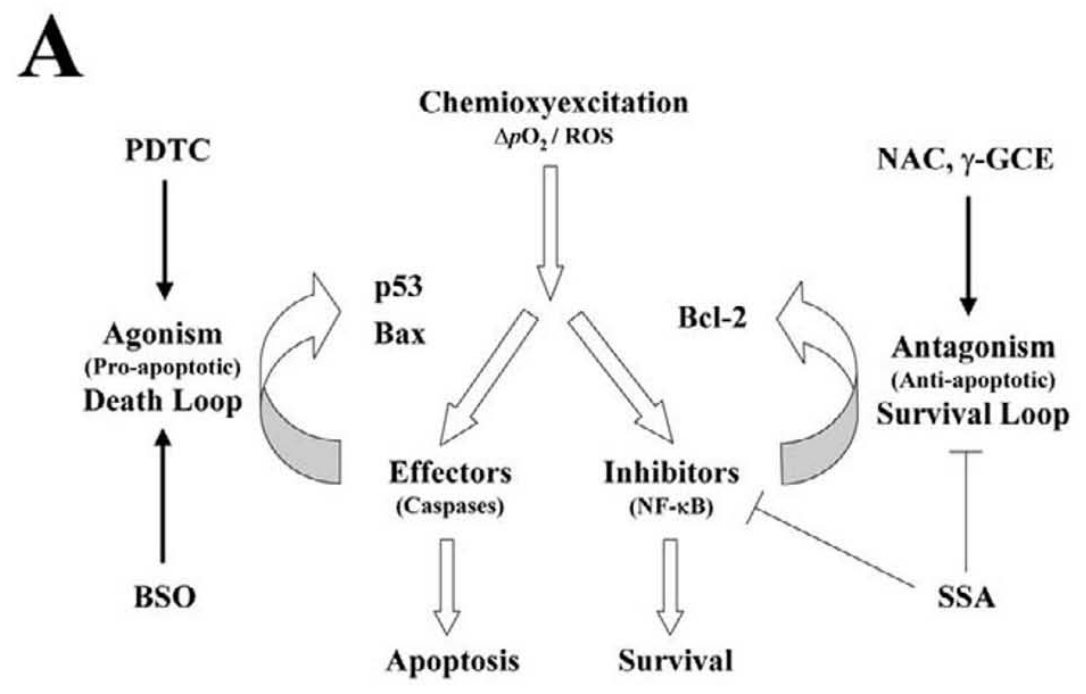

B

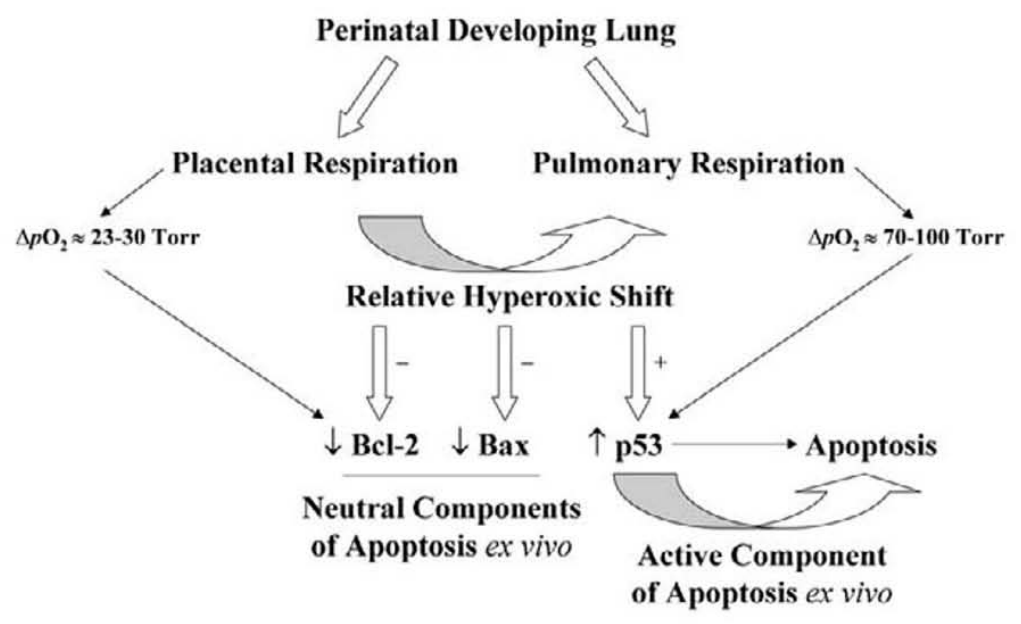

Apoptosis signaling and pathways. (A) Schematic model for apoptosis pathways in the perinatal alveolar epithelium. Exposure to ascending $\Delta p \mathrm{O}_{2}$ regimen and reactive oxygen species (ROS), a process referred to as chemioxyexcitation, triggers a signaling mechanism that could lead to either

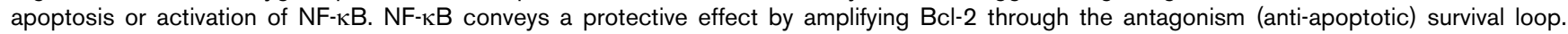
Whereas thiols such as $N$-acetyl- ${ }_{-}$-cysteine (NAC) and $\gamma$-glutamylcysteinyl-ethyl ester ( $\gamma$-GCE) promote the survival loop, sulfasalazine (SSA), a selective inhibitor of $\mathrm{NF}-\mathrm{KB}$, confers negative regulation favoring apoptosis. Glutathione depletion by $\mathrm{L}$-buthionine-( $S, R)$-sulfoximine $(\mathrm{BSO})$ upregulates the expression of Bax and p53 through activation of the agonism (pro-apoptotic) death loop, an effect that is mimicked by pyrrolidine dithiocarbamate (PDTC). The likely 'executioners' implicated in apoptosis are the caspases, the final effectors in the death machinery. (B) Schematic model for apoptosis pathways in the perinatal developing lung. The transition from placental to lung-based respiration during the birth transition period constitutes a potential signaling mechanism in the lung. This represents a relative hyperoxic shift, which allows the differential expression of signaling cofactors involved in apoptosis. The downstream pathway mediates suppression of Bcl-2 with pulmonary oxygenation, a phenomenon accompanied by down-regulating Bax. The major participant in regulating cell death ex utero is $\mathrm{p} 53$, which switches off the induction of $\mathrm{Bcl}-2$ and rather predominates Bax in controlling apoptosis within the perinatal lung. This reinforces the presumption that signaling pathways mediating apoptosis in response to oxygenation in the developing lung are p53-dependent. The $(+)$ sign indicated positive modulation (up-regulation) and (-) sign indicates negative modulation (down-regulation). 
stress [145-161]. Elucidation of the pathways of oxidantinduced apoptosis, therefore, may provide alternative therapies to scavenging the initial oxidant in those systems where excessive oxidative stress and redox disequilibrium lead to inevitable cell death.

\section{Regulation of cytokine/inflammatory signaling pathways in oxidative stress}

Accumulating evidence has linked the pathogenesis of a variety of diseases to oxidative stress $[8,12,22,27,33,37,40,41,142,145,162]$. ROS, in particular, may contribute to alveolar capillary membrane perturbations and development of lung injury [22,142-161]. Oxidative injury involves the modification of cellular macromolecules by toxic byproducts of oxygen metabolism. This condition often leads to cell death and/or the necrotic lysis of sensitive cells, resulting in the microvascular and alveolar injury typical of pulmonary oxygen toxicity $[22,37,146]$. Thus, dynamic variation in alveolar $\mathrm{pO}_{2}$ and its effect on cellular redox state may impose a direct role in modulating the pattern of gene expression and, thus, could be crucial in determining cellular fate and the inflammatory process regulated by cytokines $[36-46,166,164]$.

\section{Regulation of cytokines by ROS}

ROS play a crucial role in the initiation and progression of pathophysiological conditions. The signaling mediators involved in stress-induced lung injury are regulated, at least in part, by ROS that upregulate their secretion as part of antioxidant and immune defense mechanisms [154-164]. ROS-mediated pathways regulating cytokines are schematized in 12A For example, bronchial epithelial cells produce soluble mediators on exposure to ROS, which stimulate the release of glycoconjugates in vitro[165-167]. In addition, ROS can induce the production of IL- 6 and IL- 8 in bronchial and alveolar epithelial cells [36-46,168]. Furthermore, ROS can be released in response to a variety of stimuli, such as TNF- $\alpha$ and lipopolysaccharide [36-46,169] and they serve as intracellular signals for the activation of redoxsensitive transcription factors $[2,3,16-18,26,27,36-$ 46,164-170].

Among the mediators of oxidative stress, cytokines are of particular interest as they serve as signaling cofactors [3745]. IL-1 $\beta$, for instance, is a pleiotropic cytokine produced in response to various stimuli. It acts as a modulator of redox equilibrium [36-46]; moreover, there is substantial evidence suggesting that, among other regulatory cytokines, IL-1 $\beta$ participates in transduction signals in oxidative injury via ROS and has stimulatory effects on regulatory transcription factors mediating apoptosis [163-170]. IL-6 is responsive to inflammatory stimuli and oxidative stress [3646]. TNF- $\alpha$, a stress-induced cytokine and a mediator of oxidative injury, has been implicated in the pathogenesis of respiratory distress [36-46,164-170]. Cytokines have also been shown to induce oxidative stress in several cell models [36-46].

\section{Regulation of cytokines by redox equilibrium}

The 'biomarkers' of oxidative stress, such as antioxidant inefficiency, redox disequilibrium and derivation of oxidant radicals, may arise from conditions other than hyperoxia (oxidizing signals) per se, such as hypoxia/re-oxygenation and cytokine-dependent processes [2,3,14,16-18,26,27]. In physiological conditions, the intracellular redox status of thiols is highly reductive. Glutathione, for example, is present in high concentrations in lung epithelial lining fluid and has been reported to maintain the integrity of the airspace epithelium [171]. Glutathione depletion has been linked to the pathophysiology of idiopathic pulmonary fibrosis [171] adult respiratory distress syndrome [162,172] bronchopulmonary dysplasia [173] and cystic fibrosis [174].

Agents that induce the formation of ROS can affect redox homeostasis by upregulating antioxidant enzymes, particularly glutathione peroxidase and enzymes involved in glutathione recycling and biosynthesis [12,16,21,22,37$41,115,116,164,169,170,175-177]$. Furthermore, ROS signaling could be mediated by cytokines, whose participation in cellular pathways is modulated by redox status [3546,169-177]. Redox-mediated pathways regulating cytokines are schematized in Fig. 12B. Conversely, cytokines, which themselves are mediators of oxidative stress, have the potential to alter redox equilibrium, thereby affecting glutathione/GSSG shuttling and recycling [35-46,169177].

The immunopharmacological potential assigned to glutathione stems from established observations. IL-1-induced responses, for instance, occur through modulating the redox dynamic equilibrium [178]. In addition, ROS signaling regulating the transcription of IL-4 [179] IL-6, IL-8 [180] and TNF- $\alpha[181,182]$ is regulated by a thiol-dependent mechanism. Interestingly, antioxidants and glutathione precursors have been shown to downregulate cytokine synthesis, activation and downstream processes [35-46,169-178]. Among the many agents that are used for repletion and depletion of glutathione, NAC and L-buthionine-(S,R)-sulfoximine are, respectively, of particular importance as they exhibit antagonistic effects on a pro-inflammatory signal. NAC, an antioxidant and a glutathione precursor $[13,14,19,40,41,111]$ has the ability to abrogate cytokine biosynthesis and ROS-mediated lung injury [35-46]. In contrast, L-buthionine- $(S, R)$-sulfoximine, which depletes glutathione by irreversibly inhibiting $\gamma$-glutamylcysteine synthetase (the rate-limiting enzyme in the biosynthesis of glutathione $[39,41,48,103,104])$, has the potential to enhance cytokine secretion by upregulating ROS [35-46,181,183]. It has been reasoned that a differential manipulation of glu- 


\section{A}

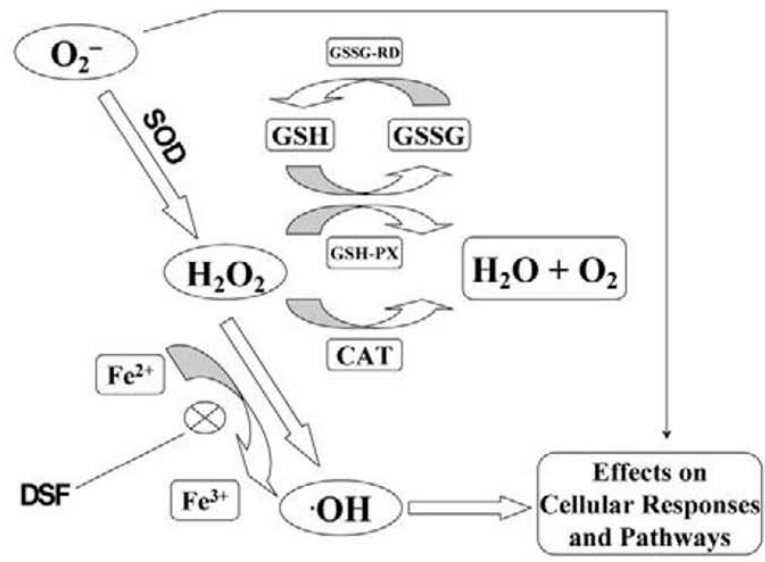

B

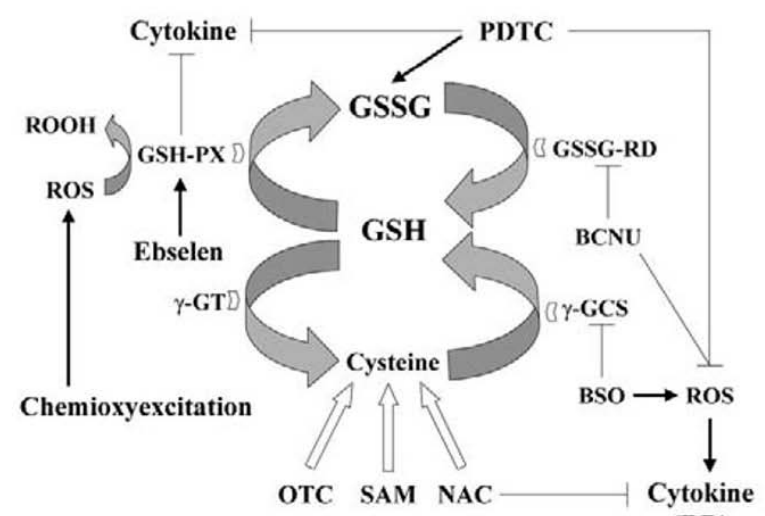

(RD)

Oxygen- and redox-mediated pathways regulating cytokines. (A) Schematic representation of the pathways leading to the generation of reactive oxygen species (ROS) and their selective dismutation. A number of major cellular enzymes that defend against oxidative stress have been conserved through evolution. Superoxide $\left(\mathrm{O}_{2}^{-\bullet}\right)$ anion is metabolized via the dismutation reaction $2 \mathrm{O}_{2}^{-\bullet}+2 \mathrm{H}^{+} \rightarrow \mathrm{O}_{2}+\mathrm{H}_{2} \mathrm{O}_{2}$. The reaction is catalyzed by superoxide oxidoreductase dismutase (SOD), which is both a cytoplasmic enzyme that is constitutively expressed and a mitochondrial enzyme that is induced in response to oxidant stress. The $\mathrm{H}_{2} \mathrm{O}_{2}$ produced by the dismutation of $\mathrm{O}_{2} \cdot \bullet$ is converted by catalase (CAT) in peroxisomes to $\mathrm{H}_{2} \mathrm{O}$ and $\mathrm{O}_{2}$ and by glutathione peroxidase (GSH-PX) in the cytoplasm, at the expense of reduced glutathione (GSH). This leads to the formation of oxidized glutathione disulphide (GSSG) that is recycled back to GSH by glutathione reductase (GSSG-RD). $\mathrm{H}_{2} \mathrm{O}_{2}$ could be further converted by another pathway involving iron $\left(\mathrm{Fe}^{2+}\right)$ into hydroxyl radical $(\bullet \mathrm{OH})$, an injurious ROS causing cellular damage. This iron-catalyzed reaction, known as the Fenton-like reaction, is impeded by the iron chelator desferrioxamine (DSF), which is also capable of neutralizing the toxicity of $\bullet \mathrm{OH}$. (B) Schematic model of thiol regulation of chemioxyexcitation-induced cytokine secretion in the alveolar epithelium. The predominant form of intracellular glutathione is GSH, which is synthesized by $\gamma$-glutamylcysteine synthetase ( $\gamma$-GCS). The molecules 2-oxothiazolidine-4-carboxylate (OTC), S-adenosyl-L-methionine (SAM) and $N$-acetyl- ${ }_{-}^{-c y s t e i n e ~ a r e ~ m a j o r ~ p r e c u r s o r s ~ o f ~ c y s t e i n e, ~ t h e ~ r a t e-l i m i t i n g ~ s u b s t r a t e ~ i n ~ t h e ~ b i o s y n t h e s i s ~ o f ~ G S H, ~ a ~ p a t h w a y ~ w h i c h ~ i s ~}$

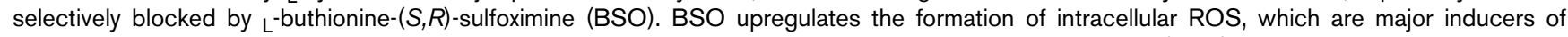
cytokine secretion. GSH is either rapidly exported, where the membrane-bound $\gamma$-glutamyl transpeptidase $(\gamma$-GT) degrades it into its subcellular components to be used for resynthesis, or is converted by oxidation to glutathione disulphide (GSSG) by glutathione peroxidase (GSH-PX) and its mimetic ebselen, at the expense of ROS (which are promptly detoxified to form peroxides, ROOH). The formation of GSSG and/or reduction of ROS downregulate the chemioxyexcitation-dependent cytokine release. GSSG is rapidly recycled back into GSH by glutathione reductase (GSSG$\mathrm{RD}$ ), a pathway which is selectively blocked by 1,3-bis-(2-chloroethyl)-1-nitrosourea (BCNU). The block leads to accumulation of GSSG, which, along with pyrrolidine dithiocarbamate, a precursor of GSSG, downregulates the formation of ROS and abrogates the cytokine-dependent sequelae. Cytokines act as major participants in the pathophysiology and aggravation of the clinical symptoms of respiratory distresses (RD). 
tathione homeostasis and shuttling antagonistically affects a proinflammatory signal. This has potential consequences for the treatment of respiratory distresses, where cytokines are recognized as major participants in pathophysiology.

\section{Conclusion and future prospects}

The molecular response to oxidative stress is regulated, in part, by redox-sensitive transcription factors [184-188]. The abrupt change in $\mathrm{pO}_{2}$, which accompanies the transition from placental to lung-based respiration, constitutes a mechanism that allows specific genetic regulation. Two transcription factors that form an integral part of the pathways augmented during this transition period are HIF-1 $\alpha$ and NF- $\kappa \mathrm{B}$, both of which are sufficiently tuned to govern a specific response in hypoxia and a relatively hyperoxic shift [184-191]. The perinatal epithelium responds to dynamic variations in $\mathrm{pO}_{2}$ by regulating their expression and activation with a unique responsiveness associated with upregulating glutathione biosynthesis, as a major intracellular thiol bearing an antioxidant potential. Modulating the antioxidant/pro-oxidant equilibrium by altering the glutathione/ GSSG redox potential evokes a genetic switch between $\mathrm{HIF}-1 \alpha$ and $\mathrm{NF}-\kappa \mathrm{B}$, an effect uncoupled from the normal pattern that is followed with a prevailing $\mathrm{pO}_{2}$.

Analysis of the apoptotic potential prevailing under various $\Delta p \mathrm{O}_{2}$ s reveals a novel differential expression of pro-apoptotic and anti-apoptotic proto-oncogenes, a phenomenon that is redox-dependent and NF- $\kappa \mathrm{B}$-sensitive. Evidence has also been provided linking oxidative stress to a proinflammatory state, regulated by oxygen- and redox-sensitive cytokines [183-192]. Thus, dynamic variation in $\mathrm{pO}_{2}$ and redox equilibrium regulates gene expression, apoptosis signaling and the inflammatory process. This regulation bears potential consequences for screening emerging targets for therapeutic intervention and manipulation under conditions of oxidative stress that mimic those seen in clinical oxygen therapy.

\section{Abbreviations}

$\mathrm{ATI} / I \mathrm{I}=$ alveolar type I/II; CAD = C-terminal transactivation domain; $\mathrm{CO}$ = carbon monoxide; $\mathrm{EPO}=$ erythropoietin; $\mathrm{GSSG}=$ glutathione oxidized disulfide; $\mathrm{H}_{2} \mathrm{O}_{2}=$ hydrogen peroxide; $\mathrm{HBS}=\mathrm{HIF}$-binding site; HIF- $\alpha=$ hypoxia-inducible factor $-1 \alpha ; \mathrm{HIF}-\mathrm{PH}=\mathrm{HIF}-\alpha$ prolyl-hydroxylase; $\mathrm{HRE}=$ hypoxia responsive element; $\mathrm{I} \mathrm{KB}=$ inhibitory $\mathrm{\kappa B}$; ICE $=\mathrm{IL}-1 \beta$ converting enzyme; $\mathrm{IL}=$ interleukin; $\mathrm{NAC}=\mathrm{N}$-Acetyl-L-cysteine; NF- $\mathrm{KB}$ $=$ nuclear factor- $\mathrm{\kappa B} ; \mathrm{NO}=$ nitric oxide; $\mathrm{O}_{2} \bullet=$ superoxide anion; $\mathrm{PDTC}$ $=$ pyrrolidine dithiocarbamate; $\mathrm{pVHL}=$ von Hippel-Lindau tumor suppressor protein; redox = reduction-oxidation; $\mathrm{ROS}=$ reactive oxygen species; SOD $=$ superoxide dismutase; TNF- $\alpha=$ tumor necrosis factor$\alpha ; \operatorname{VEGF}=$ vascular endothelial growth factor.

\section{Acknowledgements}

The author's own publications therein cited are, in part, financially supported by the Anonymous Trust (Scotland), the National Institute for $\mathrm{Bi}$ ological Standards and Control (England), the Tenovus Trust (Scotland), the UK Medical Research Council (MRC, London), the Wellcome Trust (London) (Dr. Stephen C. Land, Department of Child Health, University of Dundee, Scotland, UK) and the National Institutes of Health (NIH; Bethesda, USA) (Professor Philip E. Bickler, Department of Anesthesia and Perioperative Care, University of California, San Francisco,
California, USA). The work of the author was performed at the University of Dundee, Scotland, UK. This review was written at UCSF, California, USA. Dr John J. Haddad held the Georges John Livanos prize (London, UK) under the supervision of $\mathrm{Dr}$. Stephen C. Land and the $\mathrm{NIH}$ award fellowship (California, USA) under the supervision of Professor Philip E. Bickler. The author also appreciatively thanks Jennifer Schuyler (Department of Anesthesia and Perioperative Care) for her excellent editing and reviewing of this manuscript. I also thank my colleagues at UCSF (San Francisco, California, USA) and the American University of Beirut (AUB, Beirut, Lebanon) who have criticised the work for enhancement and constructive purposes.

\section{References}

1. Peers C, Kemp PJ: Acute oxygen sensing: Diverse but convergent mechanisms in airway and arterial chemoreceptors. Respir Res 2001, 2:145-149

2. Wenger RH: Mammalian oxygen sensing, signaling and gene regulation. J Exp Bio/ 2000, 203:1253-1263

3. Acker $\mathrm{H}$ : Mechanisms and meaning of cellular oxygen sensing in the organism. Respir Physiol 1994, 95:1-10

4. Atkinson DE, Ed: Cellular Energy Metabolism and its Regulation. Academic Press, NY; 1977

5. Boyden EA, Ed: Development of the Lung: Lung Biology in Health and Disease. Dekker, NY; 1977

6. Mason RJ, Williams MC: Type II alveolar cell: Defender of the alveolus. Am Rev Respir Dis 1977, 115:81-91

7. Fehrenbach H: Alveolar epithelia type II cell: Defender of the alveolus revisited. Respir Res 2001, 2:33-46

8. Crapo JD, Barry BE, Foscue HA, Shelburne J: Structural and biochemical changes in rat lungs occurring during exposure to lethal and adaptive doses of oxygen. Am Rev Respir Dis 1980, 122:123-143

9. Bastacky J, Lee CY, Goerke J, Koushafar H, Yager D, Kenaga L, Speed TP, Chen Y, Clements JA: Alveolar lining layer is thin and continuous: Low-temperature scanning electron microscopy of rat lung. J Appl Physiol 1995, 79:1615-1628

10. Cotton RB, Ed: Fetal and Neonatal Physiology. Saunders, $P A$ 1998

11. Wessler I, Kirkpatrick CJ: Airway epithelium: More than just a barrier. Trends Pharmacol Sci 1999, 20:52-53

12. Thompson $A B$, Robbins RA, Romberger DJ: Immunological functions of the pulmonary epithelium. Eur Respir J 1985, 8:127149

13. Haddad JJ, Land SC: $\mathrm{O}_{2}$-evoked regulation of HIF-1 $\alpha$ and NF$\kappa B$ in perinatal lung epithelium requires glutathione biosynthesis. Am J Physiol Lung Cell Mol Physiol 2000, 278:L492L503

14. Haddad JJ, Olver RE, Land SC: Antioxidant/pro-oxidant equilibrium regulates HIF- $1 \alpha$ and NF- $\mathrm{B}$ redox sensitivity: Evidence for inhibition by glutathione oxidation in alveolar epithelial cells. J Biol Chem 2000, 275:21130-21139

15. Desai TJ, Cardoso WV: Growth factors in lung development and disease: Friends or foe. Respir Res 2002, 3:2-5

16. Arrigo AP: Gene expression and the thiol redox state. Free Radic Biol Med 1999, 27:936-944

17. Sen CK, Packer L: Antioxidant and redox regulation of gene transcription. FASEB J 1996, 10:709-720

18. Sen CK: Cellular thiols and redox-regulated signal transduction. Curr Top Cell Regul 2000, 36:1-30

19. Haddad JJ, Land SC: The differential expression of apoptosis factors in the alveolar epithelium is redox sensitive and requires NF- $\mathrm{B}$ (RelA)-selective targeting. Biochem Biophys Res Commun 2000, 271:257-267

20. Haddad JJ, Choudhary KK, Land SC: The ex vivo differential expression of apoptosis signaling cofactors in the developing lung: Essential role of oxygenation during the transition from placental to pulmonary-based respiration. Biochem Biophys Res Commun 2001, 281:311-316

21. Acarregui MJ, Brown JJ, Mallampalli PK: Oxygen modulates surfactant protein mRNA expression and phospholipid production in human fetal lung in vitro. Am J Physiol 1995, 268:L818 L825

22. Chabot F, Mitchell JA, Gutteridge JMC, Evans TW: Reactive oxygen species in acute lung injury. Eur Respir J 1998, 11:745-757 
23. Acarregui MJ, Snyder JM, Mendelson CR: Oxygen modulates the differentiation of human fetal lung in vitro and its responsiveness to CAMP. Am J Physiol 1993, 264:L465-L474

24. Lubman RL, Kim K-J, Crandall ED: Alveolar epithelial barrie properties. In The Lung Scientific Foundations (Edited by: Crys tal RG, West JB, Barnes PJ)1997, 585-602

25. Eckenhoff RG, Somlyo AP: Rat lung type II cell and lamellar body: Elemental composition in situ. Am J Physiol 1988, 254:C614-C620

26. Alder V, Yin Z, Tew KD, Ronai Z: Role of redox potential and reactive oxygen species in stress signaling. Oncogene 1999, 18:6104-6111

27. van $\operatorname{der}$ Vliet $A$, Cross $C E$ : Oxidants, nitrosants and the lung. $A m$ $J$ Med 2000, 109:398-421

28. Bickler PE, Buck LT: Adaptations of vertebrate neurons to hypoxia and anoxia: Maintaining critical $\mathrm{Ca}^{2+}$ concentrations. $J$ Exp Biol 1998, 201:1141-1152

29. Richalet JP: Oxygen sensors in the organism: Examples of regulation under altitude hypoxia in mammals. Comp Biochem Physiol A Physiol 1997, 118:9-14

30. Hochachka PW, Land SC, Buck LT: Oxygen sensing and signal transduction in metabolic defense against hypoxia: Lessons from vertebrate facultative anaerobes. Comp Biochem Physiol A Physiol 1997, 118:23-29

31. Gonzalez C, Vicario I, Almaraz L, Rigual R: Oxygen sensing in the carotid body. Biol Signals 1995, 4:245-256

32. Rooney SA, Young SL, Mendelson CR: Molecular and cellular processing of lung surfactant. FASEB J 1994, 8:957-967

33. Klings $\mathrm{ES}$, Farber HW: Role of free radicals in the pathogenesis of acute chest syndrome in sickle cell disease. Respir Res 2001, 2:280-285

34. Keane MP, Strieter RM: The importance of balanced pro-inflammatory and anti-inflammatory mechanisms in diffuse lung disease. Respir Res 2002, 3:5-11

35. Chen CY, Huang YL, Lin TH: Association between oxidative stress and cytokine production in nickel-treated rats. Arch Biochem Biophys 1998, 356:127-132

36. Nesin M, Cunningham-Rundles $\mathrm{S}$ : Cytokines and neonates. $A m$ J Perinatol 2000, 17:393-404

37. Saugstad OD: Oxygen radicals and pulmonary damage. Pediatric Pulmonol 1985, 1:167-175

38. Fu K, Sarras MP Jr, De Lisle RC, Andrews GK: Expression of oxidative stress-responsive genes and cytokine genes during caerulein-induced acute pancreatitis. Am J Physiol 1997, 273:G696-G705

39. Haddad JJ: Glutathione depletion is associated with augmenting a pro-inflammatory signal: Evidence for an antioxidant/ pro-oxidant mechanism regulating cytokines in the alveolar epithelium. Cytokines Cell Mol Therap 2000, 6:177-187

40. Haddad JJ, Safieh-Garabedian B, Saadé NE, Kanaan SA, Land $\mathrm{SC}$ : Chemioxyexcitation ( $\left.\triangle p \mathrm{O}_{2} / \mathrm{ROS}\right)$ dependent release of IL$1 \beta$, IL- 6 and TNF- $\alpha$ : Evidence of cytokines as oxygen-sensitive mediators in the alveolar epithelium. Cytokine 2001, 13:138147

41. Haddad JJ, Safieh-Garabedian B, Saadé NE, Land SC: Thiol regulation of pro-inflammatory cytokines reveals a novel immunopharmacological potential of glutathione in the alveolar epithelium. J Pharmacol Exp Therap 2001, 296:996-1005

42. Rouveix B: Clinical pharmacology of cytokines. Eur Cytokine Netw 1997, 8:291-300

43. Boraschi D, Cifone MG, Falk W, Flad H-D, Tagliabue A, Martin MU: Cytokines in inflammation. Eur Cytokine Netw 1998, 9:205-212

44. Feldmann M, Brennan FM, Maini RN: Role of cytokines in rheumatoid arthritis. Annu Rev Immunol 1996, 14:397-440

45. Dinarello CA: Pro-inflammatory cytokines. Chest 2000 118:503-508

46. Nicod LP: Cytokines: Overview. Thorax 1993, 48:660-667

47. Meister A: Glutathione-ascorbic acid anti-oxidant system in animals. J Biol Chem 1994, 269:9397-9400

48. Hayes JD, McLellan LI: Glutathione and glutathione-dependent enzymes represent a coordinately regulated defense against oxidative stress. Free Radic Res 1999, 31:273-300

49. Breuille D, Obled C: Cysteine and glutathione in catabolic states. Nestle Nutr Workshop Ser Clin Perform Programme 2000, 3:173-191
50. Deplancke B, Gaskins HR: Redox control of the trans-sulfuration and glutathione biosynthesis pathways. Curr Opin Clin Nutr Metab Care 2002, 5:85-92

51. Semenza GL: Oxygen-regulated transcription factors and their role in pulmonary disease. Respir Res 2000, 1:159-162

52. Semenza GL: HIF-1 and mechanisms of hypoxia sensing. Curr Opin Cell Biol 2001, 13:167-171

53. Semenza GL: HIF-1 and human disease: One highly involved factor. Genes Dev 2000, 14:1983-1991

54. Baldwin AS: The NF- $\kappa B$ and $1 \kappa B$ proteins: New discoveries and insights. Annu Rev Immunol 1996, 14:649-681

55. Baldwin AS: The transcription factor NF- $\kappa B$ and human disease. J Clin Invest 2001, 107:3-6

56. Wang GL, Semenza GL: Purification and characterization of hypoxia-inducible factor 1. J Biol Chem 1995, 270:1230-1237

57. Sen R, Baltimore D: Multiple nuclear factors interact with the immunoglobulin enhancer sequences. Cell 1986, 46:705-716

58. Schreck R, Albermann K, Baeuerle PA: Nuclear factor $\kappa$ B: An oxidative stress-responsive transcription factor of eukaryotic cells. Free Radic Res Commun 1992, 17:221-237

59. Acker H: Cellular oxygen sensors. Ann NY Acad Sci 1994, 718:3-10

60. Gong W, Hao B, Mansy SS, Gonzalez G, Gilles-Gonzalez MA, Chan MK: Structure of a biological oxygen sensor: A new mechanism for heme-driven signal transduction. Proc Nat Acad Sci USA 1998, 95:15177-15182

61. Bunn HF, Poyton OR: Oxygen sensing and the molecular adaptation to hypoxia. Physiol Rev 1996, 76:839-885

62. Li N, Karin M: Is NF- $\kappa \mathrm{B}$ the sensor of oxidative stress? FASEB $J$ 1999, 13:1137-1143

63. Bruick RK, McKnight SL: Transcription enhanced: Oxygen sensing gets a second wind. Science 2002, 295:807-808

64. Wenger RH, Kvietikova I, Rolfs A, Camenisch G, Gassmann M: Oxygen-regulated erythropoietin gene expression is dependent on a CpG methylation-free hypoxia-inducible factor-1 DNA-binding site. Eur J Biochem 1998, 253:771-777

65. Wood SM, Wiesener MS, Yeates KM, Okada N, Pugh CW, Maxwell PH, Ratcliffe PJ: Selection and analysis of a mutant cell line defective in the hypoxia-inducible factor-1 $\alpha$-subunit (HIF-1 $\alpha$ ): Characterization of HIF-1 $\alpha$-dependent and -independent hypoxia-inducible gene expression. J Biol Chem 1998, 273:83608368

66. Fandrey J, Seydel FP, Siegers CP, Jelkman W: Role of cytochrome $\mathbf{P} 450$ in the control of the production of erythropoietin. Life Sci 1990, 47:127-134

67. Wenger RH, Gassmann M: Oxygen(es) and the hypoxia-inducible factor-1. Biol Chem 1997, 378:609-616

68. Budinger GR, Duranteau J, Chandel NS, Schumacker PT: Hibernation during hypoxia in cardiomyocytes: Role of mitochondria as the $\mathrm{O}_{2}$ sensor. $J$ Biol Chem 1998, 273:3320-3326

69. Wilson DF, Mokashi A, Chugh D: The primary oxygen sensor of the cat carotid body is cytochrome $\mathrm{c} 3$ of the mitochondrial respiratory chain. Fed Eur Biochem Soc 1994, 351:370-374

70. Hochachka PW, Buck LT, Doll CJ, Land SC: Unifying theory of hypoxia tolerance: Molecular/metabolic defense and rescue mechanisms for surviving oxygen lack. Proc Natl Acad Sci USA 1996, 93:9493-9498

71. Duranteau J, Chandel NS, Kulisz A, Shao Z, Schumacker PT: Intracellular signaling by reactive oxygen species during hypoxia in cardiomyocytes. J Biol Chem 1998, 273:11619-11624

72. Chandel NS, Maltepe E, Goldwasser E, Mathieu CE, Simon MC, Schumacker PT: Mitochondrial reactive oxygen species trigger hypoxia-induced transcription. Proc Natl Acad Sci USA 1998, 95:11715-11720

73. Chandel NS, Schumacker PT: Cells depleted of mitochondrial DNA $\left(\rho^{0}\right)$ yield insight into physiological mechanisms. FEBS Lett 1999, 454:173-176

74. Chandel NS, Schumacker PT: Cellular oxygen sensing by mitochondria: Old questions, new insight. J Appl Physiol 2000, 88:1880-1889

75. Chandel NS, McClintock DS, Feliciano CE, Wood TM, Melendez JA, Rodriguez AM, Schumacker PT: Reactive oxygen species generated at mitochondrial complex III stabilize hypoxia-inducible factor- $1 \alpha$ during hypoxia: $A$ mechanism of oxygen sensing. J Biol Chem 2000, 275:25130-25138 
76. Waypa GB, Chandel NS, Schumacker PT: Model for hypoxic pulmonary vasoconstriction involving mitochondrial oxygen sensing. Circ Res 2001, 88:1259-1266

77. Ehleben W, Bolling B, Merten E, Porwol T, Strohmaier AR, Acker $\mathrm{H}$ : Cytochromes and oxygen radicals as putative members of the oxygen sensing pathway. Respir Physiol 1998, 114:25-36

78. Porwol T, Ehleben W, Brand V, Acker H: Tissue oxygen senso function of NADPH oxidase isoforms, an unusual cytochrome aa3 and reactive oxygen species. Respir Physiol 2001 128:331-348

79. Prabhakar NR, Overholt JL: Cellular mechanisms of oxygen sensing at the carotid body: Heme proteins and ion channels. Respir Physiol 2000, 122:209-221

80. Jiang BH, Semenza GL, Bauer C, Marti HH: Hypoxia-inducible factor 1 levels vary exponentially over a physiologically relevant range of oxygen tension. Am J Physiol 1996, 271:C1172 C1180

81. Lee PJ, Jiang BH, Chin BY, lyer NV, Alam J, Semenza GL, Choi AM: Hypoxia-inducible factor-1 mediates transcriptional activation of the heme oxygenase-1 gene in response to hypoxia. $J$ Biol Chem 1997, 272:5375-5381

82. Salceda S, Caro J: Hypoxia-inducible factor-1 $\alpha$ (HIF-1 $\alpha$ ) protein is rapidly degraded by the ubiquitin-proteasome system under normoxic conditions: Its stabilization by hypoxia depends on redox-induced changes. J Biol Chem 1997, 272:22642-22647

83. Zhu H, Bunn HF: Signal transduction. How do cells sense oxygen? Science 2001, 292:449-451

84. Maxwell PH, Ratcliffe PJ: Oxygen sensors and angiogenesis. Semin Cell Dev Bio/ 2002, 13:29-37

85. Maxwell PH, Wiesener MS, Chang GW, Clifford SC, Vaux EC Cockman ME, Wykoff CC, Pugh CW, Maher ER, Ratcliffe PJ: The tumor suppressor protein VHL targets hypoxia-inducible factors for oxygen-dependent proteolysis. Nature 1999, 399:271 275

86. Cockman ME, Masson N, Mole DR, Jaakkola P, Chang GW, Clifford SC, Maher ER, Pugh CW, Ratcliffe PJ, Maxwell PH: Hypoxia inducible factor- $\alpha$ binding and ubiquitination by the von Hippel-Lindau tumor suppressor protein. J Biol Chem 2000, 275:25733-25741

87. Wykoff CC, Pugh CW, Maxwell PH, Harris AL, Ratcliffe PJ: Identification of novel hypoxia dependent and independent target genes of the von Hippel-Lindau (VHL) tumor suppressor by mRNA differential expression profiling. Oncogene 2000, 19:6297-6305

88. Jaakkola P, Mole DR, Tian YM, Wilson MI, Gielbert J, Gaskell SJ, Kriegsheim Av, Hebestreit HF, Mukherji M, Schofield CJ, Maxwel $\mathrm{PH}$, Pugh CW, Ratcliffe PJ: Targeting of HIF- $\alpha$ to the von Hippel-Lindau ubiquitination complex by oxygen-regulated prolyl hydroxylation. Science 2001, 292:468-472

89. Masson N, William C, Maxwell PH, Pugh CW, Ratcliffe PJ: Independent function of two destruction domains in hypoxia-inducible factor- $\alpha$ chains activated by prolyl hydroxylation EMBO J 2001, 20:5197-5206

90. Epstein AC, Gleadle JM, McNeill LA, Hewitson KS, O'Rourke J, Mole DR, Mukherii M, Metzen E, Wilson MI, Dhanda A, Tian YM, Masson N, Hamilton DL, Jaakkola P, Barstead R, Hodgkin J, Maxwell PH, Pugh CW, Schofield CJ, Ratcliffe PJ: C. elegans EGL-9 and mammalian homologs define a family of dioxygenases that regulate HIF by prolyl hydroxylation. Cell 2001, 107:43-54

91. Ohh M, Park CW, Ivan M, Hoffman MA, Kim TY, Huang LE, Pavletich N, Chau V, Kaelin WG: Ubiquitination of hypoxia-inducible factor requires direct binding to the $\beta$-domain of the von Hippel-Lindau protein. Nat Cell Biol 2000, 2:423-427

92. Ivan M, Kaelin WG: The von Hippel-Lindau tumor suppressor protein. Curr Opin Genet Dev 2001, 11:27-34

93. Ivan M, Kondo K, Yang H, Kim W, Valiando J, Ohh M, Salic A, Asara JM, Lane WS, Kaelin WG: HIF- $\alpha$ targeted for VHL-mediated destruction by proline hydroxylation: Implications for oxygen sensing. Science 2001, 292:464-468

94. Hoffman MA, Ohh M, Yang H, Klco JM, Ivan M, Kaelin WG: von Hippel-Lindau protein mutants linked to type $2 \mathrm{C}$ VHL disease preserve the ability to down-regulate HIF. Hum Mol Genet 2001, 10:1019-1027

95. Bruick RK, McKnight SL: A conserved family of prolyl-4-hydroxylases that modify HIF. Science 2001, 294:1337-1340
96. Lando D, Peet DJ, Whelan DA, Gorman JJ, Whitelaw ML: Asparagine hydroxylation of the HIF transactivation domain a hypoxic switch. Science 2002, 295:858-861

97. Kietzmann T, Cornesse Y, Brechtel K, Modaressi S, Jungermann K: Perivenous expression of the mRNA of the three hypoxia-inducible factor $\alpha$-subunits, HIF- $1 \alpha$, HIF- $2 \alpha$ and HIF-3 $\alpha$, in rat liver. Biochem J 2001, 354:531-537

98. Blancher C, Moore JW, Talks KL, Houlbrook S, Harris AL: Relationship of hypoxia-inducible factor (HIF)- $1 \alpha$ and HIF- $2 \alpha$ expression to vascular endothelial growth factor induction and hypoxia survival in human breast cancer cell lines. Cancer Res 2000, 60:7106-7113

99. Clifford SC, Maher ER: Von Hippel-Lindau disease: Clinical and molecular perspectives. Adv Cancer Res 2001, 82:85-105

100. Camenisch G, Stroka DM, Gassmann M, Wenger RH: Attenuation of HIF-1 DNA-binding activity limits hypoxia-inducible endothelin-1 expression. Pflugers Arch 2001, 443:240-249

101. Burke B, Tang N, Corke KP, Tazzyman D, Ameri K, Wells M, Lewis CE: Expression of HIF-1 $\alpha$ by human macrophages: implications for the use of macrophages in hypoxia-regulated cancer gene therapy. J Patho/ 2002, 196:204-212

102. Leek RD, Talks KL, Pezzella F, Turley H, Campo L, Brown NS, Bicknell R, Taylor M, Gatter KC, Harris AL: Relation of hypoxia-inducible factor-2 $\alpha$ (HIF-2 $\alpha$ ) expression in tumor-infiltrative macrophages to tumor angiogenesis and the oxidative thymidine phosphorylase pathway in human breast cancer. Cancer Res 2002, 62:1326-1329

103. Haddad JJ, Lauterbach R, Saadé NE, Safieh-Garabedian B, Land SC: $\alpha$-Melanocyte-related tripeptide, Lys- $D$-Pro-Val, ameliorates endotoxin-induced NF- $\mathrm{KB}$ translocation and activation: Evidence for involvement of an interleukin-1 $\beta^{193-195}$ receptor antagonism in the alveolar epithelium. Biochem J 2001, 355:29-38

104. Mercurio F, Manning AM: Multiple signals converging on NF- $\kappa B$. Curr Opin Cell Biol 1999, 11:226-232

105. Mercurio F, Zhu H, Murray BW: IKK-1 and IKK-2: Cytokine-activated IKB kinases essential for NF- $\mathrm{B}$ activation. Science 1997, 278:860-866

106. Carter AB, Knudtson KL, Monick MM, Hunninghake GW: The p38 mitogen-activated protein kinase is required for NF- $\mathrm{BB}-\mathrm{de}$ pendent gene expression: the role of TATA-binding protein (TBP). J Biol Chem 1998, 274:30858-30863

107. Meister A: Glutathione metabolism and its selective modification. J Biol Chem 1988, 263:17205-17208

108. Griffith OW, Meister A: Potent and specific inhibition of glutathione synthesis by buthionine sulfoximine ( $S$-n-butyl homocysteine sulfoximine). $J$ Biol Chem 1979, 254:7558-7560

109. Ema A, Hirota K, Mimura J: Molecular mechanisms of transcription activation by HLF and HIF- $1 \alpha$ in response to hypoxia: Their stabilization and redox signal induced interaction with CBP/ p300. EMBO J 1999, 18:1905-1914

110. Carrero P, Okamato K, Coumailleau P: Redox-regulated recruitment of the transcriptional activators CREB-binding protein and SRC-1 to hypoxia-inducible factor $1 \alpha . \mathrm{Mol}$ Cell Biol 2000 20:402-415

111. Haddad JJ, Land SC: A non-hypoxic, ROS-sensitive pathway mediates TNF- $\alpha$-dependent regulation of HIF-1 $\alpha$. FEBS Lett 2001, 505:269-274

112. Bernard GR: $N$-Acetylcysteine in experimental and clinical acute lung injury. Am J Med 1991, 91(3C):55S-59S

113. Brennan $P, O^{\prime} N$ eill LA: 2-Mercaptoethanol restores the ability of nuclear factor- $\kappa B(N F-\kappa B)$ to bind DNA in nuclear extracts from interleukin 1-treated cells incubated with pyrrolidine dithiocarbamate (PDTC): Evidence for oxidation of glutathione in the mechanism of inhibition of NF-KB by PDTC. Biochem J 1996, 320:975-981

114. Piette J, Piret B, Bonizzi G, Schoonbroodt S, Merville MP, LegrandPoels S, Bours V: Multiple redox regulation in NF- $\kappa$ B transcription factor activation. Biol Chem 1997, 378:1237-1245

115. Haddad JJ: L-Buthionine-(S,R)-sulfoximine, an irreversible inhibitor of $\gamma$-glutamylcysteine synthetase, augments pro-inflammatory cytokine biosynthesis: Evidence for the

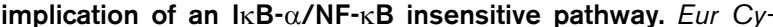
tokine Netw 2001, 12:614-624

116. Haddad JJ, Land SC, Tarnow-Mordi WO, Zembala M, KowaLczyk D, Lauterbach R: Immunopharmacological potential of selective phosphodiesterase inhibition. II. Evidence for the involve- 
ment of an inhibitory- $\kappa \mathrm{B} /$ nuclear factor- $\kappa \mathrm{B}-$ sensitive pathway in alveolar epithelial cells. J Pharmacol Exp Therap 2002, 300:567-576

117. Kerr JFR: Shrinkage necrosis: A distinct mode of cellular death J Pathol 1971, 105:13-20

118. Kerr JFR, Wyllie AH, Currie AR: Apoptosis: A basic biological phenomenon with wide-ranging implications in tissue kinetics. Br J Cancer 1972, 26:239-257

119. Wyllie $A H$, Kerr JFR, Currie AR: Cell death: The significance of apoptosis. Int Rev Cytol 1981, 68:251-305

120. Ellis RE, Yuan J, Horvitz HR: Mechanisms and functions of cell death. Annu Rev Cell Biol 1991, 7:663-698

121. Jyonouchi H: Airway epithelium and apoptosis. Apoptosis 1999, 4:407-417

122. Strasser A, O'Connor L, Dixit VM: Apoptosis signaling. Annu Rev Biochem 2000, 69:217-245

123. Carmody RJ, Cotter TG: Signaling apoptosis: A radical approach. Redox Rep 2001, 6:77-90

124. Kaufmann SH, Hengartner MO: Programmed cell death: Alive and well in the new millennium. Trends Cell Biol 2001, 11:526 534

125. Sutherland LM, Edwards YS, Murray AW: Alveolar type II cell apoptosis. Comp Biochem Physiol A Physiol 2001, 129:267-285

126. Blatt NB, Glick GD: Signaling pathways and effector mechanisms pre-programmed cell death. Bioorg Med Chem 2001, 9:1371-1384

127. Kidd VJ: Proteolytic activities that mediate apoptosis. Annu Rev Physiol 1998, 60:533-573

128. Depraetere V, Golstein P: Dismantling in cell death: Molecular mechanisms and relationship to caspase activation. Scand J Immunol 1998, 47:523-531

129. Muzio M: Signaling by proteolysis: Death receptors induce apoptosis. Int J Clin Lab Res 1998, 28:141-147

130. Cohen GM: Caspases: The executioners of apoptosis. Biochem J 1997, 326:1-16

131. Tsujimoto Y, Finger LR, Yunis J: Cloning of the chromosome breakpoint of neoplastic $B$ cells with the $t(14 ; 18)$ chromosome translocation. Science 1984, 226:1097-1099

132. Vaux DL, Cory S, Adams JM: Bcl-2 gene promotes haemopoietic cell survival and cooperates with c-myc to immortalize preB cells. Nature 1988, 335:440-442

133. Adams JM, Cory S: The Bcl-2 protein family: Arbiters of cell survival. Science 1998, 281:1322-1326

134. Anuradha CD, Kanno S, Hirano S: Oxidative damage to mitochondria is a preliminary step to caspase-3 activation in fluoride-induced apoptosis in HL-60 cells. Free Radic Biol Med 2001, 31:367-373

135. Goossens V, Stangé G, Moens K, Pipeleers D, Grooten J: Regulation of tumor necrosis factor-induced, mitochondria- and reactive oxygen species-dependent cell death by the electron flux through the electron transport chain complex I. Antioxid Redox Signal 1999, 1:285-295

136. Sastre J, Pallardó FV, Viña J: Mitochondrial oxidative stress plays a key role in aging and apoptosis. IUBMB Life 2000 , 49:427-435

137. Skulachev VP: Mitochondria in the programmed cell death phenomena; A principle of Biology: "It is better to die than to be wrong." IUBMB Life 2000, 49:365-373

138. Szibor M, Richter C, Ghafourifar P: Redox control of mitochondrial functions. Antioxid Redox Signal 2001, 3:515-530

139. Voehringer DW, Hirschberg DL, Xiao J, Lu Q, Roederer M, Lock CB, Herzenberg LA, Steinman L, Herzenberg A: Gene microarray identification of redox and mitochondrial elements that control resistance or sensitivity to apoptosis. Proc Natl Acad Sci USA 2000, 97:2680-2685

140. Yang J, Liu X, Bhalla K, Kim CN, Ibrado AM, Cai J, Peng J, Jones DP, Wang X: Prevention of apoptosis by Bcl-2: Release of cytochrome $c$ from mitochondria blocked. Science 1997 275:1129-1132

141. Mignotte B, Vayessiere JL: Mitochondria and apoptosis. Eur J Biochem 1998, 252:1-15

142. Jacobson MD: Reactive oxygen species and programmed cell death. Trends Biochem Sci 1996, 21:83-86

143. Barazzone C, Horowitz S, Donati YR, Rodriguez J, Piguet PF: Oxygen toxicity in mouse lung: Pathways to cell death. Am J Respir Cell Mol Biol 1998, 19:573-581
144. Ohse T, Nagaoka S, Arakawa Y, Kawakami H, Nakamura K: Cell death by reactive oxygen species generated from water-soluble cationic metalloporphyrins as superoxide dismutase mimics. J Inorg Biochem 2001, 85:201-208

145. Freeman BA, Panus PC, Matalon S, Buckley BJ, Baker RR: Oxidant injury to the alveolar epithelium: Biochemical and pharmacologic studies. Res Rep Health Eff Inst 1993, 54:1-30

146. Thannickal VJ, Fanburg BL: Reactive oxygen species in cell signaling. Am J Physiol Lung Cell Mol Physiol 2000, 279:L1005L1028

147. Kazzaz JA, Xu J, Palaia TA, Mantell L, Fein AM, Horowitz S: Cellular oxygen toxicity. J Biol Chem 1996, 271:15182-15186

148. Rahman I, Mulier B, Gilmour PS, Watchorn T, Donadlson K, Jeffery PK, MacNee W: Oxidant-mediated lung epithelial cell tolerance: The role of intracellular glutathione and nuclear factor$\kappa$ B. Biochem Pharmacol 2001, 62:787-794

149. Simon HU, Haj-Yehia A, Levi-Schaffer F: Role of reactive oxygen species (ROS) in apoptosis induction. Apoptosis 2000, 5:415418

150. Giles Gl, Tasker KM, Jacob C: Hypothesis: The role of reactive sulfur species in oxidative stress. Free Radic Biol Med 2001, 31:1279-1283

151. Tan S, Sagara Y, Liu Y, Maher P, Schubert D: The regulation of reactive oxygen species production during programmed cell death. J Cell Biol 1998, 141:1423-1432

152. Kannan K, Jain SK: Oxidative stress and apoptosis. Pathophysiol 2000, 7:153-163

153. Buttke TM, Sandstorm PA: Oxidative stress as a mediator of apoptosis. Immunol Today 1994, 15:7-10

154. Kehrer JP: Cause-effect of oxidative stress and apoptosis. Teratology 2000, 62:235-236

155. Ignarro LJ: Signal transduction mechanisms involving nitric oxide. Biochem Pharmacol 1991, 41:485-490

156. O'Reilly MA, Staversky RJ, Watkins RH, Maniscalco WM: Accumulation of p21 Cip1/WAF1 during hyperoxic lung injury in mice. Am J Respir Cell Mol Biol 1998, 19:777-785

157. O'Reilly MA, Staversky RJ, Stripp BR, Finkelstein JN: Exposure to hyperoxia induces p53 expression in mouse lung epithelium. Am J Respir Cell Mol Biol 1998, 18:43-50

158. Bedi A, Mookerjee B: Biological significance and molecular mechanisms of p53-induced apoptosis. Apoptosis 1998, 3:237-244

159. Méplan C, Richard MJ, Hainaut $P$ : Redox signaling and transition metals in the control of the p53 pathway. Biochem Pharmacol 2000, 59:25-33

160. Hampton MB, Fadeel B, Orrenius S: Redox regulation of the caspases during apoptosis. Ann New Acad Sci 1998, 854:328-335

161. Hall AG: The role of glutathione in the regulation of apoptosis. Eur J Clin Invest 1999, 29:238-245

162. Haselton PS, Roberts TE: Adult respiratory distress syndrome: An update. Histopathol 1999, 34:285-294

163. Haddad JJ, Land SC: Amiloride blockades lipopolysaccharideinduced cytokine biosynthesis in an I 1 B- $\alpha / N F-\kappa B-d e p e n d e n t$ mechanism: Evidence for the amplification of an anti-inflammatory pathway in the alveolar epithelium. Am J Respir Cell Mol Biol 2002, 26:114-126

164. Haddad JJ, Land SC, Tarnow-Mordi WO, Zembala M, KowaLczyk $\mathrm{D}$, Lauterbach R: Immunopharmacological potential of selective phosphodiesterase inhibition. I. Differential regulation of lipopolysaccharide-mediated pro-inflammatory cytokine (interleukin- 6 and tumor necrosis factor- $\alpha$ ) biosynthesis in alveolar epithelial cells. J Pharmacol Exp Therap 2002, 300:559-566

165. DeForge LE, Fantone JC, Kenney JS, Remick DG: Oxygen radical scavengers selectively inhibit interleukin-8 production in human whole blood. J Clin Invest 1992, 90:2123-2129

166. Desmarquest $P$, Chadelat $K$, Corroyer S: Effect of hyperoxia on human macrophage cytokine response. Respir Med 1998, 92:951-960

167. Wang Z, Malmberg $P$, Elk A: Swine dust induces cytokine secretion from human epithelial cells and alveolar macrophages. Clin Exp Immunol 1999, 115:6-12

168. Yoshida Y, Maruyama M, Fujita T: Reactive oxygen intermediates stimulate interleukin- 6 production in human bronchial epithelial cells. Am J Physiol 1999, 276:L900-L908

169. Meier B, Radeke HH, Selle S: Human fibroblasts release reactive oxygen species in response to interleukin-1 or tumor necrosis factor- $\alpha$. Biochem $J 1989,263: 539-545$ 
170. Luster MI, Simeonova PP: Asbestos induces inflammatory cytokines in the lung through redox sensitive transcription factors. Toxicol Lett 1998, 102-103:271-275

171. Cantin AM, Hubbard RC, Crystal RG: Glutathione deficiency in the epithelial lining fluid of the lower respiratory tract in idiopathic pulmonary fibrosis. Am Rev Respir Dis 1989, 139:370372

172. Bunnell E, Pacht ER: Oxidized glutathione is increased in the alveolar fluid of patients with the adult respiratory distress syndrome. Am Rev Respir Dis 1993, 148:1174-1178

173. Saugstad OD: Bronchopulmonary dysplasia and oxidative stress: Are we closer to an understanding of the pathogenesis of BPD. Acta Pediatric 1997, 86:1277-1282

174. Roum JH, Behld R, McElvancy NG: Systemic deficiency of glutathione in cystic fibrosis. J App/ Physiol 1993, 75:2419-2424

175. Haddad JJ, Saadé NE, Safieh-Garabedian B: Redox regulation of TNF- $\alpha$ biosynthesis: Augmentation by irreversible inhibition of $\gamma$-glutamylcysteine synthetase and the involvement of an $I_{\kappa} B$ $\alpha / N F-\kappa B$-independent pathway in alveolar epithelial cells. Cell Signal 2002, 14:211-218

176. Haddad JJ, Land SC: Redox/ROS regulation of lipopolysaccharide-induced mitogen-activated protein kinase (MAPK) activation and MAPK-mediated TNF- $\alpha$ biosynthesis. $\mathrm{Br} J$ Pharmacol 2002, 135:520-536

177. Haddad JJ: The involvement of $L^{-} \gamma$-glutamyl- $L^{-c y s t e i n y l-g l y c i n e ~}$ (glutathione/GSH) in the mechanism of redox signaling mediating MAPK ${ }^{\mathrm{p} 38}$-dependent regulation of pro-inflammatory cytokine production. Biochem Pharmacol 2002, 63:305-320

178. Rovin BH, Dickerson JA, Tan LC, Fassler J: Modulation of IL-1-induced chemokine expression in human mesangial cells through alterations in redox status. Cytokine 1997, 9:178-186

179. Jeannin $P$, Delneste $Y$, Lecoanet-Henchoz S: Thiols decrease human interleukin (IL)-4 production and IL-4-induced immunoglobulin synthesis. J Exp Med 1995, 182:1785-1792

180. Gosset $P$, Wallaert $B$, Tonnel AB, Fourneau $C$ : Thiol regulation of the production of TNF- $\alpha$, IL- 6 and IL- 8 by human alveolar macrophages. Eur Respir J 1999, 14:98-105

181. Neuschwander-Tetri BA, Bellezzo JM, Britton RS: Thiol regulation of endotoxin-induced release of tumor necrosis factor $\alpha$ from isolated rat Kupffer cells. Biochem J 1996, 320:1005-1010

182. Barrett EG, Johnston C, Oberdörster G, Finkelstein JN: Antioxidant treatment attenuates cytokine and chemokine levels in murine macrophages following silica exposure. Toxicol App/ Pharmacol 1999, 158:211-220

183. Tsuji F, Miyake Y, Aono H: Effects of bucillamine and $\mathrm{N}$-acetyl-cysteine on cytokine production and collagen-induced arthritis (CIA). Clin Exp Immunol 1999, 115:26-31

184. Haddad JJ, Land SC, Saadé NE, Safieh-Garabedian B: Immunomodulatory potential of thymulin- $\mathrm{Zn}^{2+}$ in the alveolar epithelium: Amelioration of endotoxin-induced cytokine release and partial amplification of a cytoprotective IL-10-sensitive pathway. Biochem Biophys Res Commun 2000, 274:500-505

185. Haddad JJ, Collett A, Land SC, Olver RE, Wilson SM: NF- $\kappa$ B blockade reduces the oxygen-evoked rise in $\mathrm{Na}^{+}$conductance in fetal alveolar cells. Biochem Biophys Res Commun 2001, 281:987-992

186. Baines DL, Ramminger SJ, Collett A, Haddad JJ, Best OG, Land SC, Olver RE, Wilson SM: Oxygen-evoked $\mathrm{Na}^{+}$transport in rat fetal distal lung epithelial cells. J Physiol 2001, 532:105-113

187. Haddad JJ, Safieh-Garabedian B, Saadé NE, Land SC: The biphasic immunoregulation of pyrimidylpiperazine $(\mathrm{Y}-40138)$ is IL10 sensitive and requires NF- $\mathrm{B}$ targeting in the alveolar epithelium. Br J Pharmacol 2001, 133:49-60

188. Haddad JJ, Land SC: Nuclear factor- $\kappa$ B blockade attenuates but does not abrogate lipopolysaccharide-dependent tumor necrosis factor- $\alpha$ biosynthesis in alveolar epithelial cells. Biochem Biophys Res Commun 2001, 285:267-272

189. Haddad JJ: VX-745: Vertex Pharmaceuticals. Curr Opin Investig Drugs 2001, 2:1070-1076

190. Haddad JJ, Land SC: Redox signaling-mediated regulation of lipopolysaccharide-induced proinflammatory cytokine biosynthesis in alveolar epithelial cells. Antioxid Redox Signal 2002 4:179-193

191. Haddad JJ, Fahlman CS: Nuclear factor- $\kappa B$-independent regulation of lipopolysaccharide-mediated interleukin- 6 biosynthesis. Biochem Biophys Res Commun 2002, 291:1045-1051
192. Hadad : Recombinant TNF- $\alpha$ mediated regulation of the $\mid \kappa B-\alpha /$ $N F-\kappa B$ signaling pathway: Evidence for the enhancement of pro- and anti-inflammatory cytokines in alveolar epithelial cells. Cytokine 2002, 17:301-310 